\title{
Modelling the Dynamics of Corruption and Unemployment with Heterogeneous Labour
}

\author{
King Yoong Lim* \\ Accepted on October 13, 2018
}

\begin{abstract}
This paper presents an endogenous growth model with heterogeneous labour, endogenous unemployment, and public sector corruption. Unlike most previous studies, the model does not separate public officials and private individuals into two distinct groups. Instead, taking up bureaucratic appointment as a public servant is modelled as an occupational choice, which then allows for the endogenous determination of the proportion of public officials, the share of corrupt officials among them, and the public investment efficiency of the economy. The dynamics of endogenous corruption and unemployment are studied using numerical policy experiments based on a stylized representation of a middle-income African economy with high corruption and unemployment. The main finding is that, large-scale public infrastructure push has no effect on raising growth in an economy with high corruption. However, if preceded by social and anti-corruption policies that successfully induce a structural change, it will then be effective in raising growth.
\end{abstract}

JEL Classification Number: H30, H54, O41

Keywords: Economic Growth, Corruption, Public Sector Efficiency, Unemployment

*Nottingham Business School. Email: king.lim@ntu.ac.uk. I am grateful to PierreRichard Agénor, Tajudeen Ibrahim Adebisi, Chisom Ubabukoh, and three anonymous referees for helpful feedback on previous versions. Their comments have vastly contributed to the improvement of the content of this article. The views expressed are my own. 


\section{Introduction}

In most developing economies, notably lower-middle income economies with poor institutional and governance quality, public officials, often well-educated groups of elites, are in unique positions to abuse their powers in the various forms of corruption. Public sector corruption, broadly defined as the illegal or unauthorised profiteering by public officials abusing their authoritative positions, can manifest in different forms - including embezzlement of public funds, fraud claims, and direct receipts of bribery - and offers substantial personal gains at the costs of society, hence potentially causing significant damage to socio- and economic development (Blackburn et al., 2011).

In the literature of public sector corruption, the contributions made in the form of microeconomic and applied empirical studies over the last decade have been enormous ${ }^{1}$, with development economists now having a general consensus on the long-term adverse impact of corruption on growth and development. Indeed, corruption activities often transcend direct practicing of fraud and bribery, especially when there are principal-agent considerations in the duties of public officials (Banerjee, 1997; Guriev, 2004; Fredriksson, 2010). As such, corruption can be persistent over time, hence adversely affecting the levels of private investment (Mauro, 1997), human capital accumulation (Ehrlich and Liu, 1999), income certainty (Dzhumashev, 2016), and inequality (Blackburn and Forgues-Puccio, 2009) over the long run. These are supported by findings in the vast empirical literature, where evidence shows that most developing countries with poor institutions and high levels of corruption have experienced poor growth performance. For instance, Mauro (1997) and Delavallade

\footnotetext{
${ }^{1}$ Examples of microeconomic models with public sector rent-seeking and corruption include, non-exhaustively, Cule and Fulton (2005), Infante and Smirnova (2009), Ryvkin and Serra (2012), Fredriksson (2014), and relevant references therein. These studies examine corruption manifesting in different forms, but not their implications to economic growth in a general equilibrium, macroeconomic context.
} 
(2006) document evidence that corruption tends to lead to a diversion of public expenditure from growth-promoting productive spending to non-productive spending. Moreover, the adverse effects of corruption on growth are shown by Méndez and Sepúlveda (2006) and Dzhumashev (2016) to be both nonlinear and non-monotonic, with the latter two suggesting the possible existence of a non-zero level of corruption that could be growth-enhancing.

Of the many forms of public sector corruption, public sector rent-seeking and embezzlement of funds associated with procurement of public infrastructure projects have been the most popular choice for growth theorists in modelling corruption in theoretical macroeconomic models (for instance, Bose et al., 2008; Blackburn et al., 2011; Chakraborty and Dabla-Norris, 2011). To our knowledge, notwithstanding the fact that public procurement accounts for nearly 70 percent of many central governments' expenditure, this is mainly due to two reasons: (i) asymmetric information associated with procurement of most large-scale public infrastructure/capital good investments exists and leads to principal-agent problem, hence creating the opportunities for public officials to embezzle funds (Sarte, 2000; Del Monte and Papagni, 2001); (ii) as motivated in studies such as Delavallade (2006) and Dzhumashev (2014), the two-way relationship between corruption and government spending tends to affect the allocation and composition of public spending. With most endogenous growth models having public capital as a key growth driver, the embezzlements taking place through procurement therefore provides the most direct means to examine the two-way relationship, as well as their effects on different spending allocation.

Despite the many contributions, there remains knowledge gaps in the body of literature on public sector corruption and growth in developing, middleincome economies. For instance, despite plenty of anecdotal evidence and often attract attention from development practitioners and policymakers alike, 
the corruption-unemployment nexus has received little attention from the academic community. As often argued by the World Bank, and in contributions such as Ndikumana (2006) and Bakare (2011), both corruption and unemployment are often two of the most pressing policy issues facing many developing economies. High level of corruption, notably embezzlement of public funds, has been a persistent issue in many developing countries. ${ }^{2}$ These contributed to low-quality public investment, discouraged private physical and human capital investment, and consequently results in dampened growth, which in turn perpetuates unemployment. Sustained unemployment then results in economic instability and an increase in illegal activities (often in the forms of black market), which then makes it easier and cheaper for corruption practices. Indeed, faced with a weakened economy with large gaps in infrastructure, a lack of skills, and poor public service delivery, the goals of fighting corruption and tackling unemployment have become the main policy priorities of many Sub-Saharan African economies. ${ }^{3}$ Second, given the lack of attention paid to corruption-unemployment nexus, to our knowledge, almost all macroeconomic of corruption models with public embezzlement do not account for structural unemployment and skill acquisitions. ${ }^{4}$ This is despite the World

\footnotetext{
${ }^{2}$ In fact, globally, embezzlement of public funds have been one of the persistent form of public sector corruption. For instance, according to UN Crime Survey statistics, between the two periods of 1998-99 and 2005-2006, the number of officially reported embezzlement cases in the world is 213,477 and 235,758 respectively for the 2 periods. This is despite many developing economies opted not to respond to the survey. This, couple with the inherent difficulties in actually finding one to be guilty of embezzling public funds (the average conviction rate of the UN surveyed sample of developing countries during the period is only about 20 percent), makes embezzlement a persistent form of public sector corruption in the developing world.

${ }^{3}$ For instance, upon taking office, the current Nigerian President Buhari's administration identified the "twin-high" problem corruption and unemployment as main policy priorities, against the backdrop of continuing poor public service delivery and sluggish growth.

${ }^{4}$ Indeed, even among empirical contributions, to our knowledge, Lackó (2004) and Bouzid (2016) are the only studies that examine the nexus between corruption and unemploymentalbeit youth unemployment - and establish empirically a two-way relationship. Nevertheless, these empirical exercises are neither anchored by microfoundations nor general equilibrium framework.
} 
Bank (2012) suggested an indirect effect of corruption on unemployment: the reduced public investment quality results in lower growth and income, which in turn impedes job creation in the long-run. There is therefore a role for labour market reforms to potentially tackle corruption issues too. Effective labour market reforms are necessary to facilitate human capital development, improve social cohesion, and this can consequently reduce the incentive for corruption - to preview, these are key features that policy experiments using the analytical model developed in this article is able to produce. ${ }^{5}$ Third, given the lack of attention paid to corruption-unemployment nexus, the present literature lacks an analytical model that allows for endogenous determination of variables such as proportion of skilled labour in public sector, and proportion of public officials that are corrupt (in most models, both are treated as exogenously given, distinct groups of agents that are treated separately from the households who consume and save). Fourth, to our knowledge, none of the (comparatively) large existing analytical literature on corruption focusing on embezzlement has examined transitional dynamics of policies. These studies therefore cannot make claims with regards to the dynamic trade-offs (long-term versus instantaneous) of policies.

We address these 4 shortcomings in the existing literature by formally developing a dynamic endogenous growth model with endogenous determination of unemployment and public sector corruption. In terms of existing studies, the heterogeneous abilities and endogenous human capital accumulation features of Spinesi (2009) and Agénor and Lim (2017) are integrated into a model with public capital procurement, similar to Chakraborty and Dabla-Norris (2011), to examine the many policy issues cited, including studying the transitional dynamics of policies.

\footnotetext{
${ }^{5}$ The impact of labour market reforms in reducing structural unemployment and raising growth is well-documented in studies such as Agénor et al. (2007), Bernal-Verdugo et al. (2012), and Anand and Khera (2016).
} 
To preview, there are three main novel features in the model. First, in the process of public procurement, distinctions are made between actual and reported/claimed spending on public capital. This creates a discrepancy between actual and reported/claimed spending on public capital goods. As public investment budgetary process is based on the latter, this can result in ineffectiveness of public infrastructure investment, a finding similar in spirit to those empirically documented for health and education spending in poorly governed countries by Rajkumar and Swaroop (2008). Indeed, the public investment efficiency index, which is usually treated as a parameter in the literature, is endogenously determined in this model. Second, our policy simulation results show that, the seemingly (and usually classified as) unproductive social spending aimed at raising minimal income has a role to play in closing the gap between actual and reported/claimed spending, therefore raising public investment efficiency. When such a reform reduces corruption to a large magnitude, this can then serve as impetus to a structural change and restore the effectiveness of public infrastructure investment in driving growth. Lastly, unlike most growth models of corruption, we do not separate public officials and private individuals into two distinct groups. Instead, taking up bureaucratic appointment as a public servants is modelled as an occupational choice - albeit one that has specification that ensures complete bureaucratic participation - which then allows for the proportion of public officials, as well as the share among those that are corrupt, to be endogenously determined. In my knowledge, this is among the first instances where the dynamics of endogenous corruption and unemployment are examined together in a model of endogenous growth. As multilateral organisations alike have moved forward with designing more concrete measurement of corruption, this allows us to provide a direct theoretical counterpart where variables such as the share of corrupt officials and public investment efficiency can be directly parameterised and studied as policy 
variables.

The remainder of the article is organised as follows. Section 2 presents the model. Section 3 defines the balanced growth equilibrium and discusses its properties. Model parameterisations are reported in Section 4 to reflect the initial state of a typical middle-income Sub-Saharan African economy facing high rates of unemployment and corruption, though with some degree of industrialisation. In Section 5, various policy experiments are analysed and discussed. Section 6 concludes the article.

\section{The Model}

Time is discrete with $t=0,1, \ldots, \infty$, and the economy is populated by twoperiods lived individuals (adulthood and old age) with different innate abilities. Population is constant at $\bar{N}$. Each individual is risk neutral and endowed with one unit of time in each period of life. In old age, time is allocated entirely to leisure. In the beginning of adulthood, individuals decide whether to acquire skills or to directly enter into the workforce as unskilled workers. The acquisition of skills is necessary if one were to work as public officials, or skilled workers in the private sector (specifically, non-routine task in the design sector). Both the unskilled and skilled workers can be unemployed, of which then they collect an unemployment benefit/cash transfer from an unemployment insurance fund financed by firms' payroll contribution and administered by the government. In addition, the government also operates a general budget, where expenditure consists primarily of public investment and public emoluments. The latter consists of the wages paid to the public officials employed to procure for public capital goods using funds allocated from the former.

Corruption arises from the incentive of an official to appropriate public funds by falsifying information to the government during the public procurement process. This creates a discrepancy between actual and reported/claimed 
spending on public capital goods. As public investment budgetary process is based on the latter, this can result in ineffectiveness of public infrastructure investment, unless the gap is closed.

Lastly, the private production sectors consist of a final good sector and a consolidated intermediate goods and design sector. Unemployment prevails in the economy due to labour market imperfection associated with union bargaining of wages.

In terms of existing studies, the unemployment and private sector aspects of the model are most similar to Agénor and Lim (2017), while the public sector features the "corruption due to uncertainty associated with procurement costs" attributes introduced initially in Bose et al. (2008), and subsequently modified by Blackburn et al. (2011) and Haque and Kneller (2015).

\section{$2.1 \quad$ Individuals}

Individuals have identical preferences but are born with different abilities, indexed by $a$. Ability is instantly observable by all and follows a continuous distribution with density function $f(a)$ and cumulative distribution function $F(a)$, with support $(0,1)$. For tractability, $a$ is assumed to be uniformly distributed on its support. Each individual maximises utility and decides whether to engage in market work as an unskilled worker or (after spending $\varrho$ to acquire skills) as a skilled worker. Specifically, an adult with ability $a$ can enter the labour force at the beginning of period $t$ as an unskilled worker and earn the net wage $(1-\tau) w_{t}^{U}$, which is independent of the worker's ability. Alternatively, the individual may choose to first spend a fraction $\varrho \in(0,1)$ of his/her time endowment at the beginning of adulthood in advanced training, incur a cost $t c_{t}>0$, and then enter the labour force for the remainder of the period as a skilled worker, either working in the private sector as a design worker, or in the public sector as a public official. The former earns after-tax wage of $(1-\tau) w_{t}^{S}$, 
while the latter earns non-taxable wage, $w_{t}^{S}$. During training, workers earn no income. All individuals can either be employed (superscript $E$ ) or unemployed (superscript $L$ ). If unemployed, individuals earn an unemployment benefit/cash transfer from the government, $b_{t}$, which is not taxable.

Let $c_{t \mid t+n}^{h, j}$ denote consumption at period $t+n$ of an individual $h=U, S Y, S G$, either employed or unemployed, $j=E, L$, born at the beginning of period $t$, with $n=0,1$. It is assumed that individuals treat his/her consumptions in both periods as perfect substitutes, with the discounted utility function specified as:

$$
V_{t}^{h, j}=c_{t \mid t}^{h, j}+\frac{c_{t \mid t+1}^{h, j}}{1+\rho}, h=U, S Y, S G, \quad j=E, L
$$

where $\rho>0$ is the common discount rate parameter. ${ }^{6}$

Generally, in the absence of corruption possibility, the period-specific budget constraints are given by

$$
\begin{gathered}
c_{t \mid t}^{U, j}+s_{t}^{U j}= \begin{cases}(1-\tau) w_{t}^{U} & \text { if } j=E \\
b_{t} & \text { if } j=L\end{cases} \\
c_{t \mid t}^{S, j}+s_{t}^{S, j}= \begin{cases}(1-\tau)\left[(1-\varrho) w_{t}^{S}-t c_{t}\right] & \text { if } h=S Y, j=E \\
(1-\varrho) b_{t}-t c_{t} & \text { if } j=L \\
(1-\varrho) w_{t}^{S}-t c_{t} & \text { if } h=S G, j=E\end{cases} \\
c_{t \mid t+1}^{h, j}=\left(1+r_{t+1}\right) s_{t}^{h}, \quad h=U, S Y, S G, \quad j=E, L
\end{gathered}
$$

where $s_{t}^{h, j}$ is savings, $1+r_{t+1}$ the gross rate of return between periods $t$ and $t+1$, and $\tau \in(0,1)$ the tax rate.

Note that the budget constraint specified above for a public official applies only to non-corrupt officials, since at the point when training decision would

\footnotetext{
${ }^{6}$ Given that individuals work only in one period and consume during old-age, the issue of risk aversion has minimal implications on the central issues investigated in this article. Perfect substitutes is therefore a reasonable utility specification that would vastly simplify the analytical complications involved in deriving the two threshold conditions later (to train or not train; to corrupt or not corrupt). Also, as seen later, the use of a log-utility function is impractical as a corrupt official who gets caught would have all the income confiscated and left with a net negative payoff.
} 
have to be made, an individual does not factor into the possibility of a corruption opportunity arisen when he has been employed as a public official. As such, an individual finds it optimal to train if and only if his expected (aftertax) earnings as a skilled worker, adjusted for the time and pecuniary costs of training, exceeds the expected earnings of an unskilled worker:

$$
(1-\varrho)\left(\zeta_{t}^{S Y}(1-\tau) w_{t}^{S}+\zeta_{t}^{S G} w^{S}+\zeta_{t}^{S L} b_{t}\right)-t c_{t} \geq\left(1-\zeta_{t}^{U L}\right)(1-\tau) w_{t}^{U}+\zeta_{t}^{U L} b_{t},
$$

where the going wage, or the unemployment benefit, is weighted by the respective probability of being either employed or unemployed, $\zeta_{t}^{h} \in(0,1)$, for $h=S Y, S G, S L, U Y, U L .^{7}$ In specifying (5), we assume that an individual knows if his/her ability is above or below the threshold $a^{C}$ and can therefore decide whether to acquire skills or not at the beginning of adulthood.

In line with Galor and Moav (2000), Tanaka and Iwaisako (2009), and following the specifications of Agénor (2016), Agénor and Canuto (2017), and Agénor and Lim (2017), the training cost is assumed to be proportional to the expected skilled wage when employed and varies inversely with the individual's ability, which determines how fast (or how well) he or she can learn:

$$
t c_{t}=\mu(1-\varrho)\left(\zeta_{t}^{S Y}(1-\tau) w_{t}^{S}+\zeta_{t}^{S G} w_{t}^{S}\right) / a^{\chi}
$$

with $\mu, \chi \in(0,1)$.

As shown in the Appendix, the threshold level of ability $a_{t}^{C}$ such that all individuals with ability higher than $a_{t}^{C}$ choose to undergo training is given by

$$
a_{t}^{C}=\mu^{1 / \chi}\left\{1-(1-\varrho)^{-1} \frac{\left(1-\zeta_{t}^{U L}\right)(1-\tau) w_{t}^{U}+\zeta_{t}^{U L} b_{t}-(1-\varrho) \zeta_{t}^{S L} b_{t}}{\zeta_{t}^{S Y}(1-\tau) w_{t}^{S}+\zeta_{t}^{S G} w_{t}^{S}}\right\}^{-1 / \chi}
$$

The productivity of unskilled workers is constant regardless of ability and is normalised to unity. Given (7), the raw supply of unskilled labour, $N_{t}^{U}$,

\footnotetext{
${ }^{7}$ Equation (5) is assumed to hold as a strict inequality for the individual with the highest ability, that is, $a=1$, otherwise nobody would choose to become skilled.
} 
is equal to the number of individuals in the population who choose not to undergo training:

$$
N_{t}^{U}=\bar{N} \int_{0}^{a_{t}^{C}} f(a) d a=a_{t}^{C} \bar{N} .
$$

The raw supply of skilled workers, at any time $t$, is $\bar{N} \int_{a_{t}^{C}}^{1} f(a) d a=(1-$ $\left.a_{t}^{C}\right) \bar{N}$. However, the average skill level of workers with ability $a \in\left(a_{t}^{C}, 1\right)$ who have undergone training equals $\left(a_{t}^{C}+1\right) / 2$; thus, the effective supply of skilled labour at time $t$, can be defined as

$$
N_{t}^{S}=\frac{1-\left(a_{t}^{C}\right)^{2}}{2} \bar{N}
$$

\subsection{Final Good}

The perfectly competitive final good production sector is characterised by routine task, populated by a continuum of firm $i, i \in(0,1)$, each producing a homogeneous good, $Y_{t}^{i}$, which requires the use of unskilled labour, $N_{i, t}^{U Y}$, private capital, $K_{i, t}^{P}$, a combination of intermediate inputs, $x_{i, s, t}, s \in\left(0, M_{t}\right)$, and aggregate public capital, $K_{t}^{G}$.

The production function is specified as

$$
Y_{t}^{i}=\left[\frac{K_{t}^{P}}{\bar{N} \zeta}\right]^{l}\left(N_{i, t}^{U Y}\right)^{\beta^{U}}\left(K_{i, t}^{P}\right)^{\alpha}\left[\int_{0}^{M_{t}} x_{i, s, t}^{\eta} d s\right]^{\gamma / \eta}\left(K_{t}^{G}\right)^{\varpi},
$$

where $\beta^{U}, \alpha, \gamma \in(0,1), \omega>0, \beta^{U}+\alpha+\gamma=1, \eta \in(0,1)$ and $1 /(1-\eta)>1$ is (the absolute value of) the price elasticity of demand for each intermediate good, and $K_{t}^{P}$ is the aggregate private capital. Constant returns prevail with respect to private inputs, and production is subject to a standard ArrowRomer type of externality associated with the aggregate private capital stock, though subject to congestion by the total population size at $\zeta>0$.

Assuming full depreciation, firm $i$ 's profits are defined as

$$
\Pi_{i, t}^{Y}=Y_{t}^{i}-\int_{0}^{M_{t}} P_{t}^{s} x_{i, s, t} d s-w_{t}^{U} N_{i, t}^{U Y}-r_{t} K_{i, t}^{P} .
$$


Each firm maximises profits subject to (11) with respect to labour, private capital, and quantities of intermediate goods $x_{i, s, t}, \forall s$, taking factor prices and $M_{t}$ as given. This yields, in standard fashion,

$$
\begin{gathered}
w_{t}^{U}=\beta^{U} \frac{Y_{i, t}}{N_{i, t}^{U Y}}, \\
r_{t}=\alpha\left(\frac{Y_{i, t}}{K_{i, t}^{P}}\right) . \\
x_{i, s, t}=\left(\frac{\gamma Z_{i, t}}{P_{t}^{s}}\right)^{1 /(1-\eta)}, \quad s=1, \ldots M_{t}, \\
Z_{i, t}=Y_{i, t} / \int_{0}^{M_{t}}\left(x_{i, s, t}\right)^{\eta} d s .
\end{gathered}
$$

\subsection{Intermediate Goods and Designs}

Given the focus is on a middle-income economy with some degree of industrialization, a Romerian specification is used for the intermediate goods (IG) sector, where monopolistically competitive market structure is assumed. Nonetheless, these may be interpreted as imported technology-based imitation activities, instead of innovation. To produce an IG, a corresponding design has to be purchased from a counterpart design firm. The design firms are the private sector employers of skilled labour in this economy. There is only one producer of each input $s$, and each of them must pay a fee to use the design. Production of each unit of an IG uses a single unit of the final good. Each IG producer sets a price to maximise profits, given the perceived demand function for its good. With a standard optimal price of $P_{t}^{s}=\frac{1}{\eta} . \forall s=1, \ldots M_{t}$, the quantity demanded at this price is $x_{s, t}=\left(\gamma \eta Z_{t}\right)^{1 /(1-\eta)}, \forall s$, which under symmetry $\int_{0}^{M_{t}} x_{s, t}^{\eta} d s=M_{t} x_{t}^{\eta}$, yields

$$
x_{t}=\gamma \eta\left(\frac{Y_{t}}{M_{t}}\right)
$$

with maximum profit of

$$
\Pi_{t}^{I}=(1-\eta) \gamma\left(\frac{Y_{t}}{M_{t}}\right)
$$


Following Agénor and Canuto (2015), IG firms are assumed to last only one period, and that patents are auctioned off randomly to a new group of firms in each period. Thus, each producer of a new intermediate good holds a patent only for the period during which it is bought, implying monopoly profits during that period only; yet patents last forever. By arbitrage, therefore,

$$
Q_{t}=\Pi_{t}^{I}
$$

Meanwhile, firms engaged in design generate blueprints for new intermediate goods, using the same technology. Each firm produces a single design and there is no aggregate uncertainty. The aggregate stock of designs evolves according to

$$
M_{t+1}-M_{t}=\left(\frac{K_{t}^{G}}{K_{t}^{P}}\right)^{\varsigma_{1}^{m}} M_{t} \frac{(1-\varrho) N_{t}^{S Y}}{\bar{N}},
$$

which uses skilled workers, and depends on the public-private capital ratio (Agénor and Alpaslan, 2014) and the stock of designs (Jones, 2005). To eliminate scale effects, it is the ratio of workers to total population that is specified in the production function. ${ }^{8}$

Profit maximisation by the design firms (by selecting $N_{t}^{S Y}$ ) involves maximising $\Pi_{t}=Q_{t}\left(M_{t+1}-M_{t}\right)-\left[w_{t}^{S}(1-\varrho) N_{t}^{S Y}\right]$ subject to the skilled wage, yields a first-order condition of

$$
w_{t}^{S}=\frac{Q_{t}\left(k_{t}^{G}\right)^{\varsigma_{1}^{m}} M_{t}}{N_{t}^{S Y}},
$$

where $k_{t}^{G}=K_{t}^{G} / K_{t}^{P}$. In turn, by substituting in the expression for $Q_{t}$, the skilled wage in the private sector is given by

$$
w_{t}^{S}=\frac{\left[\left(k_{t}^{G}\right)^{\varsigma_{1}^{m}}(1-\eta) \gamma\right] Y_{t}}{N_{t}^{S Y}}
$$

\footnotetext{
${ }^{8}$ See Dinopoulos and Segerstrom (1999).
} 


\subsection{Wages-Setting}

To obtain a model equilibrium with non-zero unemployment, we adopt the straightforward labour market institution of a monopoly union framework. Following Agénor and Lim (2017), two separate but similar unions existone each for the unskilled and skilled workers in the private sector-where the wage-setting process takes place between a centralised trade union and firms. The unions' objectives are to maximise the expected current income of its members, subject to wage and employment targets, taking the existing capital stock (for unskilled) and design stock (for skilled) as given. The unions therefore do not internalise the effect of future wages on the firm's decision to accumulate capital - and thus future labour demand, effectively making it a static optimisation problem at every period $t .^{9}$

Specifically, for $h=U, S$, the union sets $w_{t}^{U}$ or $w_{t}^{S}$ with the objective of maximising a utility function that depends on deviations of both employment and wages from their target levels, subject to the labour demand schedule for each type. Normalising the employment target to zero, the union's utility function takes the standard form

$$
\mathfrak{V}_{t}^{h}=\left(w_{t}^{h}-w_{t}^{h T}\right)^{\xi^{h}}\left(N_{t}^{h}\right)^{1-\xi^{h}},
$$

where $h=U, S,{ }^{h} \in(0,1)$, and $N_{t}^{h}$ is given in (12). The term $w_{t}^{h T}$ measures the union's target wage, whereas $\xi^{h}$ reflects the relative importance that the union attaches to wage deviations from that target.

Maximising (22) with respect to $w_{t}^{h}$ gives the actual wage as a mark-up

\footnotetext{
${ }^{9}$ An alternative specification is to consider a Nash wage bargaining process, in which case then the labour demand is derived from the bargaining process instead of firms' profit maximisation decision. However, given that the two types of workers work in different sectors, and that the difference in bargaining features will not result in significant difference to the unemployment-corruption nexus, we use the more convenient monopoly union model where unions set wage taking labour demand schedule of firms as given. See Bhattacharyya and Gupta (2015) for a direct comparison of the two specifications.
} 
(which is increasing in $\xi^{h}$ ) over the target wage,

$$
w_{t}^{h}=\left(\frac{1-\xi^{h}}{1-2 \xi^{h}}\right) w_{t}^{h T} .
$$

We specify the target wages to be linearly dependent on the minimum level of income a worker would otherwise earn if unemployed, $b_{t}$, adjusted (negatively) to the unemployment rate of the respective category of workers, as in

$$
w_{t}^{h T}=b_{t}\left(\theta_{t}^{h}\right)^{-\varkappa^{h}} w_{0}^{h}, \quad h=U L, S L
$$

where $\varkappa^{U L}, \varkappa^{S L}>0, w_{0}^{h}$ and $\theta_{t}^{h}, h=U L, S L$ denote shift parameter and the unemployment rate (in proportion of $\bar{N}$ ) of labour category $h$, with

$$
b_{t}=\kappa_{t} \frac{Y_{t}}{\bar{N}}
$$

where $\kappa_{t}>0$ is an endogenously determined (by the government's allocation) benefit/social security indexation ratio variable. Consistent with most specification, it is also indexed to the level of per capita income in each period $t^{10,11}$

Using (23), (24), and (25), we can derive an alternative expression for $w_{t}^{U}$ and $w_{t}^{S}$, as in

$$
w_{t}^{U}=\kappa_{t}\left(\frac{1-\xi^{U}}{1-2 \xi^{U}}\right) w_{0}^{U}\left(\frac{Y_{t}}{\bar{N}}\right)\left(\theta_{t}^{U L}\right)^{-\varkappa^{U}}
$$

and

$$
w_{t}^{S}=\kappa_{t}\left(\frac{1-\xi^{S}}{1-2 \xi^{S}}\right) w_{0}^{S}\left(\frac{Y_{t}}{\bar{N}}\right)\left(\theta_{t}^{S L}\right)^{-\varkappa^{S}}
$$

respectively.

\footnotetext{
${ }^{10}$ Unlike Agénor and Lim (2017), which focuses on examining the impacts of various labour market policies in developed and upper-middle income economies, the focus of this paper, the corruption-unemployment nexus, is usually more relevant in a developing economy contextmost of which have non-binding minimum wage and unemployment benefits. As such, $b_{t}$ in this context can be interpreted as some form of social security payment or cash transfers to meet the minimum income of the unemployed.

${ }^{11}$ In relatively parsimonious partial equilibrium model, such as Heer and Morgenstern (2005), the unemployment benefit is indexed to previous period's earnings. While our indexation is to the same-period income per capita, $\kappa_{t}$ is endogenous here, which then allows for much richer dynamic feedback from the system into the benefit indexation.
} 


\subsection{Public Sector}

Based on the public procurement framework of Blackburn et al. (2011) and Haque and Kneller (2015), the government is specified to hire public officials (paying non-taxable market salary, $w_{t}^{S}$ ) to procure capital goods to be used for public investment. Given the non-taxable nature of wage income for public officials, skilled labour will always prefer to work for the government than in the private sector. This ensures the allocation of talent condition in Acemoglu and Verdier (1998) would hold, as the government can ensure complete bureaucratic participation just by paying the skilled market wage, $w_{t}^{S}$. As shown later, to finance the public officials' salaries, the government allocates a constant fraction, $v_{G}$, of the government revenue each period as public emoluments.

On aggregate, the government demands $g_{t}$ amount of capital goods, which is a constant fraction of the final output in the economy, $\psi Y_{t}$ (Blackburn et al. 2010; Blackburn et al. 2011). To ensure model stability, we assume that the government keeps $\psi$ constant over time by setting $\psi=K_{0}^{G} / Y_{0}$, in accordance to the initial public capital-final output ratio, $K_{0}^{G} / Y_{0}$. This means capital goods demanded in each period $t$ is budgeted according to the initial ratio, and even as the ratio changes over time, the demand planned by the government in a specific period remains as a constant share of the output in said period. As such, there exists a planning gap, where there is a discrepancy between the aggregate public capital level demanded by the government for the economy, and the actual supply of the public capital-final output ratio in each period $t, K_{t}^{G} / Y_{t}{ }^{12}$

Further, and more critical to understand corruption in the model, there

\footnotetext{
${ }^{12}$ As would be seen in the policy experiments later, we analyse an additional case where $\psi_{t}$ is endogenous and varies over time. In this case, the government is assumed to attempt to close the planning gap between the aggregate demand and supply of public capital goodto-final output ratio by resetting its demand based on the new public capital good-to-final output ratio in each period.
} 
exists a discrepancy between actual spending on public capital goods and claimed/reported spending. In each period $t$, each public official is responsible to procure $g_{t} / N_{t}^{S G}$ raw units of capital goods and claim the corresponding spending off the total governmental allocation to public infrastructure investment. However, the public capital goods have to be quality-adjusted, as in Blackburn et al. (2011) and Chakraborty and Dabla-Norris (2011), a process that requires the public officials to procure for a quality component. There are two states of purchases in terms of quality: high-quality or low-quality. A low-quality purchase yields only $\Upsilon<1$ unit of quality despite costing 1 unit of final good. A high-quality purchase always yields 1 unit of quality, though it is subject to higher and uncertain cost, indexed by $\phi$. Due to this uncertainty, each official faces different realized cost drawn at random, with $\phi$ assumes a uniform distribution with support $\phi_{t} \in\left(1, \phi^{\max }\right)$. The government is aware of the overall distribution of the cost, though it does not observe the true cost and quality, therefore have to rely on public officials. As such, potential corruption opportunity arises because an official can falsify information by over-reporting the unit cost. To avoid corner solution, it is also specified that a corrupt official will not be able to claim the maximum amount, $\phi^{\max }$, because the government knows the upper-bound value, therefore will always claim his/her respective optimal cost at time t, $\phi_{t}$.

A public official that is not corrupt is always going to maximise public capital good quality per unit of expenditure. Specifically, the official procures $g_{t} / N_{t}^{S G}$ units of (quality-adjusted) capital goods (with quality of 1 ) at the actual realized cost. On average, the claim made by a public official is therefore $\bar{\phi}=\left(1+\phi^{\max }\right) / 2{ }^{13}$ In this instance, a public official will then earn $(1-\varrho) w_{t}^{S}$ (recall that a constant fraction of time, $\varrho$, has been spent in acquiring skills).

\footnotetext{
${ }^{13}$ Note that this does not mean that actual realized cost will be the same. Due to the cost uncertainty, the actual realized cost for each official will be different, as this is drawn from the uniform distribution $\phi$. However, on average, given the statistical properties of a uniform distribution, its mean is easily derivable as $\bar{\phi}$.
} 
However, there is corruption opportunity due to the (upside) cost uncertainty. If a public official were to be corrupt, he/she procures $g_{t} / N_{t}^{S G}$ units of capital goods (but with low-quality, $\Upsilon\left[g_{t} / N_{t}^{S G}\right]$ ), pays the actual realized cost incurred ( $\phi$ is again different for each corrupt official, but on average, we can deduce from the statistical mean of uniform distribution that the actual spending is $\bar{\phi}$ per unit $\left[\bar{\phi}\left(g_{t} / N_{t}^{S G}\right)\right]$, but claims an inflated amount that is optimal, $\phi_{t} \in\left(\bar{\phi}, \phi^{\max }\right)$, making a personal gain of $\left(\phi_{t}-\bar{\phi}\right)\left(g_{t} / N_{t}^{S G}\right)$ on top of the wage income $^{14}$. These different variables (and their outcome) concerning the public procurement process are summarised in Table 1.

Due to an imperfect monitoring effort made by the government, it is assumed, for simplicity, that a corrupt public official faces a random probability, $p \in(0,1)$ of avoiding being caught, and probability, $1-p$, of being caught. ${ }^{15}$ Public officials being caught are fined the full amount of his wage income, therefore left with zero income. In this instance, the government is only able to recover $z$ fraction of the embezzled funds. For a corrupt public official, with an exogenous probability $p$, the official succeeds in evading detection and has an income of $\left[(1-\varrho) w_{t}^{S}-t c_{t}\right]+\left(\phi^{\text {optimal }}-\bar{\phi}\right)\left[g_{t} / N_{t}^{S G}\right]-h c_{t}$, where $h c_{t}$ is the resources spent by a corrupt official to attempt to conceal his/her behaviour. With a probability $1-p$, the official is apprehended and confiscated of all his income. In this case, the net payoff is then the training cost in-

\footnotetext{
${ }^{14}$ By implication, in the context of existing studies, this is similar to saying that those public officials whose actual realised cost falls between $\bar{\phi}$ and $\phi^{\max }$ is corruptible, while those facing cost below $\bar{\phi}$ is non-corruptible. As such, in strict mathematical terms, the share of corrupt officials in the model refers to the share of corrupt officials out of the total public officials susceptible to corruption.

${ }^{15}$ In line with the standard Shapiro-Stiglitz shirking model, this means the probability of being detected is related one-to-one with the monitoring intensity (see van Schaik and de Groot (2000) for an example). Thus, although given at the level of each individual public official, it is in principle treated as a choice variable by the government, which would normally vary with unit monitoring costs. Later, for the purposes of sensitivity analysis, this probability of getting caught-hence the monitoring intensity-is endogenised and allowed to vary across time, depending on the total share of corrupt individuals in the economy, $\varepsilon_{t} N_{t}^{S G} / \bar{N}$
} 
curred to become skilled, $t c_{t}$, and the concealment cost, $h c_{t}$. As such, and given the utility functional form in (1), a public official will embezzle public funds if his/her expected discounted utility is at least as good as not doing so, $p V_{t}^{S G, c, p}+(1-p) V_{t}^{S G, c, 1-p} \geq V_{t}^{S G, n c}$. This gives:

$p\left[\left((1-\varrho) w_{t}^{S}-t c_{t}\right)+\left(\phi_{t}-\frac{1+\phi^{\max }}{2}\right) \frac{g_{t}}{N_{t}^{S G}}\right]+(1-p)\left[-t c_{t}\right]-h c_{t} \geq(1-\varrho) w_{t}^{S}-t c_{t}$.

Similar to Haque and Kneller (2015), $h c_{t}$ is assumed to be an increasing function of the illegal income, $\left(\phi_{t}-\bar{\phi}\right)\left(g_{t} / N_{t}^{S G}\right)$, given by

$$
h c_{t}=\left(\frac{\theta_{t}^{S L}}{\theta_{t}^{U L}}\right)^{\delta}\left(\phi_{t}-\frac{1+\phi^{\max }}{2}\right) \frac{g_{t}}{N_{t}^{S G}},
$$

where $\delta>0$. Unlike their specification, the concealment cost does not depend on the share of corrupt officials $\left(\varepsilon_{t}\right)$, which is endogenous in this model. ${ }^{16}$ Instead, it depends on the ratio of skilled over unskilled unemployment rate in the economy, which is a novel feature of this model. The former is consistent with the uemployment-as-disciplinary device specification of most Shapiro-Stiglitz type of models, where the higher the skilled unemployment rate is, the more costly for an official to corrupt, hence the concealment cost. In contrast, the higher the unskilled unemployment rate is in the economy, it is easier/cheaper for the corrupt officials to conceal their behaviours, which is consistent with the informal sector interpretation that sustained unemployment tends to translate to an increase in hidden economic activities - arena where embezzled funds can be concealed.

Holding the incentive condition (28) in equality, and using $g_{t}=\psi Y_{t}$, (6), (12), (29), we can derive a threshold value for the unit cost, $\phi_{t}^{*}$, above which

\footnotetext{
${ }^{16}$ The convenient specification of Haque and Kneller (2015) implies easier concealment when corruption becomes more prevalent, which contradicts the model property of Lui (1986). It also relies on the fact that the total number of public officials $\left(N_{t}^{S G}\right)$ is constant. It is not suitable here due to the endogeneity of both $N_{t}^{S G}$ and $\varepsilon_{t} . \varepsilon_{t}$ is determined based on the distribution of $\phi$ here, and in an economy where $N_{t}^{S G}$ is expanding, the concealment cost may not be increasing with the $N_{t}^{S G}$.
} 
a public official will choose to be corrupt:

$$
\phi_{t}^{*}=\bar{\phi}+\frac{(1-p)}{p}(1-\varrho) \frac{\Phi_{t}}{\psi} \frac{N_{t}^{S G}}{N_{t}^{S Y}}\left[\frac{1}{p}-\left(\frac{\theta_{t}^{S L}}{\theta_{t}^{U L}}\right)^{\delta}\right]^{-1},
$$

where $\Phi_{t}=\left[\left(k_{t}^{G}\right)^{\varsigma_{1}^{m}}(1-\eta) \gamma\right]$.

On aggregate, the law of large numbers means probability of individual level equals the actual outcomes. At any time $t$, within the support $\left(\bar{\phi}, \phi^{\max }\right)$, we know that the number of corrupt officials equals $N_{t}^{S G} \int_{\phi_{t}^{*}}^{\phi^{\max }} f(\phi) d \phi$. The share of corrupt officials (as percentage of total public officials), $\varepsilon_{t}$, can therefore be computed as:

$$
\varepsilon_{t}=\frac{\phi^{\max }-\phi_{t}^{*}}{\phi^{\max }-\bar{\phi}}
$$

where $\phi_{t}^{*}$ and $\bar{\phi}$ are as defined.

As such, the share of corrupt public officials, $\varepsilon_{t}$, in this model is determined by the (inverse) distribution of the profiteering opportunity to inflate expenditure, within the support range of $\left(\bar{\phi}, \phi^{\max }\right)$. However, for the non-corrupt group, $1-\varepsilon_{t}$, the aggregate outcome is different from if there is no corruption. Specifically, the average claim made by non-corrupt public officials would equal $\left(1+\phi_{t}^{*}\right) / 2$, instead of $\bar{\phi}$ (if there is totally no corruption), because there are officials who are susceptible to corruption but opt not to corrupt. On aggregate, the actual spending on (quality-adjusted) unit of public capital goods procured is therefore

$$
\begin{aligned}
G_{t}^{K} & =\left(1-\varepsilon_{t}\right) N_{t}^{S G} \frac{g_{t}}{N_{t}^{S G}}+\varepsilon_{t} N_{t}^{S G} \Upsilon \frac{g_{t}}{N_{t}^{S G}} \\
& =\left[1-\varepsilon_{t}(1-\Upsilon)\right] g_{t},
\end{aligned}
$$

while the total claimed/reported spending filed by the public officials add up 
to $^{17}$

$$
\begin{aligned}
G_{t}^{I} & =\left(1-\varepsilon_{t}\right) N_{t}^{S G} \frac{\left(1+\phi_{t}^{*}\right)}{2} \frac{g_{t}}{N_{t}^{S G}}+\varepsilon_{t} N_{t}^{S G} \frac{\left(\phi_{t}^{*}+\phi^{\max }\right)}{2} \frac{g_{t}}{N_{t}^{S G}} \\
& =\left\{\left(1-\varepsilon_{t}\right)\left[(0.5)\left(1+\phi_{t}^{*}\right)\right]+\varepsilon_{t}\left[(0.5)\left(\phi_{t}^{*}+\phi^{\max }\right)\right]\right\} g_{t} .
\end{aligned}
$$

\subsection{Public Finance}

In terms of the fiscal budget, the government is assumed to maintain a balanced budget in each period and cannot issue bonds to borrow. To finance its general outlays, the government levies a tax on non-public sector workers' wages at the rate $\tau$, plus the salaries confiscated from apprehended corrupt officials. These outlays consist of the public emolument, $G_{t}^{G}$, the funds allocated for public investment (public capital goods purchase in this context), $G_{t}^{I}$, another funds allocated to provide minimum income in the form of social security payment/unemployment benefits to those unemployed in the economy, $G_{t}^{S}$, and spending on other items, $G_{t}^{O}$, assuming to be non-productive. It imposes no fees for its services.

The government's general budget is given by

$$
\begin{aligned}
& G_{t}^{G}+G_{t}^{I}+G_{t}^{S}+G_{t}^{O} \\
= & \tau\left\{w_{t}^{U} N_{t}^{U Y}+N_{t}^{S Y}\left[(1-\varrho) w_{t}^{S}-t c_{t}\right]\right\} \\
& +(1-p) \varepsilon_{t}(1-\varrho) w_{t}^{S} N_{t}^{S G}+(1-p) \varepsilon_{t} N_{t}^{S G} z\left(\phi_{t}-\frac{1+\phi^{\max }}{2}\right) \frac{\psi Y_{t}}{N_{t}^{S G}}
\end{aligned}
$$

where the total outlays are financed by the tax income and the recovered funds from successful detection of corruption (the first term is the the fined wage, and the second term is the constant $z$ fraction recovered from embezzled

\footnotetext{
${ }^{17}$ Note that the specification, (33), is only valid when there is an interior solution for the system. In other words, there has to be leakage and therefore non-zero corruption rate in the economy. Indeed, it can be shown that, the benchmark dynamic system characterizing the model solutions derived eventually is only solvable for non-zero value of $\varepsilon_{t}$. In other words, the special case of a corner solution of $\varepsilon_{t}=0$ does not exist for the benchmark dynamic system.
} 
funds $)^{18}$, with public emolument given by

$$
G_{t}^{G}=(1-\varrho) w_{t}^{S} N_{t}^{S G}
$$

Shares of spending are constant fractions of government revenues:

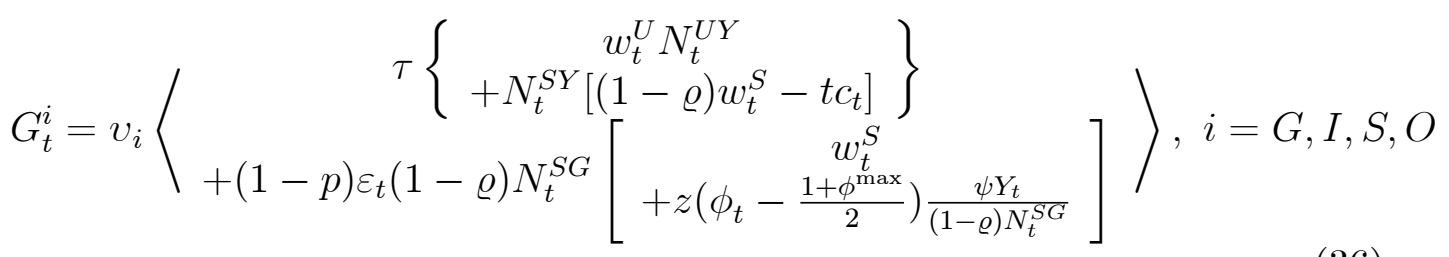

where $v_{i} \in(0,1)$. Combining (34) and (36) therefore yields

$$
v_{I}+v_{G}+v_{S}+v_{O}=1
$$

The tax-free nature of public officials' wage income means skilled workers will always prefer to work as government officials, though the total number employed at any period $t, N_{t}^{S G}$, is largely determined by the share of government revenues allocated to expenditure on emoluments. As seen in Appendix, equating (35) and (36) for $G_{t}^{G}$, we can derive an expression for the share of public officials in the economy, $\theta_{t}^{S G}=N_{t}^{S G} / \bar{N}$, as:

$$
\theta_{t}^{S G}=\frac{v_{G} \tau\left\{\frac{\beta^{U}}{\Phi_{t}}+\left(1-\frac{\mu(1-\tau)}{\left[0.5\left(1+a_{t}^{C}\right)\right] \chi} \frac{\theta_{t}^{S Y}}{\theta_{t}^{S}}\right)\right\} \theta_{t}^{S Y}}{\left\{\begin{array}{c}
{\left[1-v_{G}(1-p) \varepsilon_{t}\right]+v_{G} \tau \frac{\mu}{\left[0.5\left(1+a_{t}^{C}\right)\right] \chi} \frac{\theta_{t}^{S Y}}{\theta_{t}^{S}}} \\
+(1-p) \varepsilon_{t} z\left(\phi_{t}-\frac{1+\phi^{\max }}{2}\right) \frac{\psi}{(1-\varrho)} \frac{Y_{t}}{N}
\end{array}\right\}}
$$

where again, $\Phi_{t}=\left[\left(k_{t}^{G}\right)^{\varsigma_{1}^{m}}(1-\eta) \gamma\right]$, and $\theta_{t}^{h}, h=U, S, U Y, S Y, S G$ denote the proportion of individuals of the respective category $h$ in the adult population $\bar{N}$.

\footnotetext{
${ }^{18}$ In practice, for most kleptocracy or corruption cases, even when a public official is found guilty, the embezzled funds are usually not recovered in full. Further, the legal process involved in tracing and recovering of the funds tend to be a lengthy process. The embezzled funds therefore often end up being written off from the government account. Given the generally weak institutional capacity of a developing economy, we can expect $z$ to be very small, if not zero.
} 
In terms of public investment, the government's allocation, $G_{t}^{I}$ is based on the total claims made by public officials, not the actual spending incurred. As such, even with assumed full depreciation, the evolution of public capital stock, $K_{t+1}^{G}=G_{t}^{K}$, but $K_{t+1}^{G} \neq G_{t}^{I}$, with the difference being the public funds embezzled by the corrupt officials. The evolution of public capital is therefore characterised by

$$
\begin{aligned}
K_{t+1}^{G} & =G_{t}^{K} \\
& =\left[1-\varepsilon_{t}(1-\Upsilon)\right] g_{t} \\
& =\left[1-\varepsilon_{t}(1-\Upsilon)\right] \psi Y_{t} .
\end{aligned}
$$

Let $\varphi_{t}$ denotes a variable measuring the efficiency of public investment [a measure often modelled as exogenous, time-invariant parameter in standard growth models with public investment (see Agénor, 2012)]. As shown in the Appendix, we can compute $\varphi_{t}$ by dividing (39) with (36), which yields

$$
\begin{gathered}
\varphi_{t}=\frac{G_{t}^{K}}{G_{t}^{I}}=\frac{\left[1-\varepsilon_{t}(1-\Upsilon)\right] \psi}{\left\{v _ { I } \left[\tau \beta^{U}+\tau \Phi_{t}(1-\varrho)\left(1-\frac{\mu}{\left[0.5\left(1+a_{t}^{C}\right)\right] x}\left(\zeta_{t}^{S Y}(1-\tau)+\zeta_{t}^{S G}\right)\right)\right.\right.} \frac{Y_{t}}{K_{t}^{P}} . \\
\left.\left.+(1-p) \varepsilon_{t}(1-\varrho) \Phi_{t} \frac{\theta_{t}^{S G}}{\theta_{t}^{S Y}}+(1-p) \varepsilon_{t} z\left(\phi_{t}-\frac{1+\phi^{\max }}{2}\right) \psi\right]\right\}
\end{gathered}
$$

In terms of the unemployment insurance/social security fund, the flows' accounting can be expressed as

$$
\begin{aligned}
b_{t}\left[\theta_{t}^{U L}+(1-\varrho) \theta_{t}^{S L}\right] \bar{N}= & v_{S}\left\{\tau\left\{w_{t}^{U} N_{t}^{U Y}+N_{t}^{S Y}\left[(1-\varrho) w_{t}^{S}-t c_{t}\right]\right\}\right. \\
& +(1-p) \varepsilon_{t}(1-\varrho) w_{t}^{S} N_{t}^{S G} \\
& \left.+(1-p) \varepsilon_{t} z\left(\phi_{t}-\frac{1+\phi^{\max }}{2}\right) \psi Y_{t}\right\}
\end{aligned}
$$

which as shown in the Appendix, allows us to derive an expression for the benefit indexation variable, $\kappa_{t}$ :

$$
\kappa_{t}=\frac{\left\{\begin{array}{c}
v_{S}\left[\tau \beta^{U}+\tau \Phi_{t}(1-\varrho)\left(1-\frac{\mu}{\left[0.5\left(1+a_{t}^{C}\right)\right] x}\left(\zeta_{t}^{S Y}(1-\tau)+\zeta_{t}^{S G}\right)\right)\right. \\
\left.+(1-p) \varepsilon_{t}(1-\varrho) \Phi_{t} \frac{\theta_{t}^{S G}}{\theta_{t}^{S Y}}+(1-p) \varepsilon_{t} z\left(\phi_{t}-\frac{1+\phi^{\max }}{2}\right) \psi\right]
\end{array}\right\}}{\theta_{t}^{U L}+(1-\varrho) \theta_{t}^{S L}} .
$$




\subsection{Labour Market Identities and Savings-Investment Balance}

To close the model, the equilibrium condition of the market for unskilled labour (and the relevant shares in terms of ratios) is given by

$$
N_{t}^{U}=N_{t}^{U L}+N_{t}^{U Y}, \text { and } \theta_{t}^{U}=\theta_{t}^{U L}+\theta_{t}^{U Y},
$$

where $\theta_{t}^{U}=N_{t}^{U} / \bar{N}$, which from (8) equals to $a_{t}^{C}$. Thus, the probability of employment for an unskilled individual, $\zeta_{t}^{U Y}$, and the probability of an unskilled individual becoming unemployed, $\zeta_{t}^{U L}$, are given respectively by

$$
\zeta_{t}^{U Y}=\frac{N_{t}^{U Y}}{N_{t}^{U}}=\frac{\theta_{t}^{U Y}}{\theta_{t}^{U}}, \text { and } \zeta_{t}^{U L}=1-\zeta_{t}^{U Y}=\frac{N_{t}^{U L}}{N_{t}^{U}}=\frac{\theta_{t}^{U L}}{\theta_{t}^{U}}
$$

The equilibrium condition of the market for (effective) skilled labour is given by

$$
N_{t}^{S}=N_{t}^{S Y}+N_{t}^{S G}+N_{t}^{S L}, \quad \text { and } \theta_{t}^{S}=\theta_{t}^{S Y}+\theta_{t}^{S G}+\theta_{t}^{S L}
$$

The employment and unemployment probabilities for skilled workers are given by

$$
\begin{aligned}
\zeta_{t}^{S Y} & =\frac{N_{t}^{S Y}}{N_{t}^{S}}=\frac{\theta_{t}^{S Y}}{\theta_{t}^{S}}, \quad \zeta_{t}^{S G}=\frac{N_{t}^{S G}}{N_{t}^{S}}=\frac{\theta_{t}^{S G}}{\theta_{t}^{S}} \\
\text { and } \zeta_{t}^{S L} & =1-\zeta_{t}^{S Y}-\zeta_{t}^{S G}=\frac{N_{t}^{S L}}{N_{t}^{S}}=\frac{\theta_{t}^{S L}}{\theta_{t}^{S}} .
\end{aligned}
$$

For the saving-investment balance, assuming full depreciation, the savinginvestment balance requires private capital in $t+1$ to be equal to savings in period $t$ by all individuals born in $t-1:^{19}$

$$
\begin{aligned}
K_{t+1}^{P}= & \left(s_{t}^{U, Y} N_{t}^{U Y}+s_{t}^{U, L} N_{t}^{U L}\right)+\left[s_{t}^{S Y} N_{t}^{S Y}++s_{t}^{S, L} N_{t}^{S L}\right. \\
& \left.+s_{t}^{S G, N c}\left(1-\varepsilon_{t}\right) N_{t}^{S G}+s_{t}^{S G, c, p} \varepsilon_{t} N_{t}^{S G, c, p}\right] .
\end{aligned}
$$

\footnotetext{
${ }^{19}$ For convenience, we assume that the corrupt officials (that are not caught) are able to invest the embezzled funds and earn standard market interest rate. Alternative, we could have specified the model such that the embezzled funds can be invested in the black market and earns a fraction of the market interest rate. This does not make a significant difference to the results.
} 


\section{Dynamic System and Balanced Growth Equi- librium}

In this economy, an imperfect equilibrium with corruption and unemployment is a sequence of consumption and saving allocations $\left\{c_{t \mid t}^{h, j}, c_{t \mid t+1}^{h, j}, s_{t}^{h, j}\right\}_{t=0}^{\infty}$, for $h=$ $U, S Y, S G, j=E, L$, prices of production inputs $\left\{w_{t}^{U}, w_{t}^{S}, r_{t+1}\right\}_{t=0}^{\infty}$, existing blueprint varieties $\left\{M_{t}\right\}_{t=0}^{\infty}$, private capital $\left\{K_{t}^{P}\right\}_{t=0}^{\infty}$, public capital $\left\{K_{t}^{G}\right\}_{t=0}^{\infty}$, such that, given initial stocks $M_{0}, K_{0}^{P}, K_{0}^{G}>0$,

a) all individuals, skilled or unskilled, employed or unemployed, publicly or privately employed, maximise utility by choosing consumption subject to their intertemporal budget constraint, taking factor prices, the tax rate, and the unemployment benefit as given;

b) the public officials maximise utility by choosing the cost to report (hence to corrupt or not to corrupt), taking the overall distribution of the purchase cost, $\phi$, the probability of being detected, the quality of the final goods, and the public funds allocated for public investment as given;

c) firms in the final good sector maximise profits by choosing labour, private capital, and intermediate inputs, taking factor prices as given;

d) intermediate producers set prices so as to maximise profits, given the perceived aggregate demand curve for their product;

e) design firms maximise profits by choosing skilled labour, taking wages, patent prices, and public-private capital ratio as given;

$f$ ) each equilibrium design fee extracts all profits made by the corresponding intermediate producer; and

$g$ ) the trade union sets wages so as to maximise its utility, subject to the demand for labour by firms in the final good sector;

h) the final good market clears;

i) unemployment of both categories of workers prevails; and

j) non-zero share of corrupt officials prevails among the public officials.

A balanced growth equilibrium is an equilibrium with corruption and unemployment in which

a) $\left\{c_{t \mid t}^{h, j}, c_{t \mid t+1}^{h, j}, s_{t}^{h, j}\right\}_{t=0}^{\infty}$, for $h=U, S Y, S G, j=E, L$, and $K_{t}^{P}, K_{t}^{G}, Y_{t}$, $w_{t}^{U}, w_{t}^{S}, b_{t}$, grow at the constant, endogenous rate $1+\gamma$, implying that the blueprint-private capital ratio and the public-private capital ratio is constant;

$b$ ) the rate of return on capital, $1+r_{t+1}$, is constant; 
c) the threshold level of individuals who choose to remain unskilled, $a_{t}^{C}$, is constant;

d) the threshold level of cost above which public officials opt to corrupt, $\phi_{t}^{*}$, is constant;

$e$ ) the fractions of the skilled and unskilled labour force employed in manufacturing, $\theta_{t}^{U Y}$ and $\theta_{t}^{S Y}$, and the fraction of officials employed in the public sector, $\theta_{t}^{S G}$, are constant;

$f$ ) the proportion of the public officials who are corrupt, $\varepsilon_{t}$, is constant;

$g$ ) the benefit indexation variable (as a ratio of income per capita), $\kappa_{t}$, is constant;

$h$ ) the price of intermediate goods $P_{t}$ and the fee $Q_{t}$, is constant;

i) skilled and unskilled unemployment rates, $\theta_{t}^{U L}$ and $\theta_{t}^{S L}$, are constant; and

$j$ ) employment and unemployment probabilities, $\zeta_{t}^{U Y}, \zeta_{t}^{S Y}, \zeta_{t}^{S G}$, and $\zeta_{t}^{U L}$, $\zeta_{t}^{S L}$ are constant.

In terms of properties of the equilibrium, as shown in the Appendix, the dynamics of the model are mainly driven by the two difference equations of $K_{t}^{G} / K_{t}^{P}$ and $M_{t} / K_{t}^{P}$, as well as core static equations in terms of the final goodprivate capital ratio, $Y_{t} / K_{t}^{P}$, the threshold level of ability (or equivalently the share of unskilled workers), $a_{t}^{C}$, the shares of skilled workers in final good production and public sector, $\theta_{t}^{S Y}$ and $\theta_{t}^{S G}$, the proportion of public officials that are corrupt, $\varepsilon_{t}$, the threshold level of procurement cost, $\phi_{t}^{*}$, the share of unskilled workers in final good production, $\theta_{t}^{U Y}$, the shares of skilled and unskilled workers in unemployment, $\theta_{t}^{S L}$ and $\theta_{t}^{U L}$, and the benefit indexation ratio, $\kappa_{t}$. For the case in which $\psi_{t}=K_{t}^{G} / Y_{t}$ is endogenous and varies over time, the relevant $\psi$ 's in the derived equations are replaced by $K_{t}^{G} / K_{t}^{P} / Y_{t} / K_{t}^{P}$, and a relatively more complicated system is solved separately.

A key step in deriving the equilibrium growth rate is to establish the restrictions needed on the congestion parameters in (10). Let $m_{t}=M_{t} / K_{t}^{P}$, this involves setting $\beta^{U}=\zeta \iota$ and $\alpha+\gamma / \eta+\iota+\omega=1$. Rearranging terms, we can then yield an expression for $Y_{t}$ as a linear function of $K_{t}^{P}$ :

$$
Y_{t}=\frac{\left(k_{t}^{G}\right)^{\omega /(1-\gamma)}(\gamma \eta)^{\gamma /(1-\gamma)}}{\left[\left(\theta_{t}^{U Y}\right)^{\beta^{U}}\right]^{-1 /(1-\gamma)}}\left\{m_{t}^{(1-\eta) / \eta}\right\}^{\gamma /(1-\gamma)} K_{t}^{P} .
$$

Lastly, the growth rate of final output, $1+\gamma_{t}$, can be determined by noticing that the growth rate of final output equals the growth rate of physical capital. 
The expression is derived and shown in the Appendix. Given the complexity of the system, both the solutions and the stability of the system cannot be studied analytically. However, it is established numerically based on a parameterised model by solving for an initial balanced growth equilibrium that satisfies the properties defined earlier and verifying that following a shock, the system converges to a new equilibrium.

\section{Model Parameterisation}

To examine the model properties and to study the general equilibrium effects of policy parameters, we parameterise the system based on a typical Sub-Saharan African middle-income economies. Many middle-income African economies that have successfully built up an industrial base, such as Kenya, South Africa, and to a lesser extent, the non-oil sector of Nigeria ${ }^{20}$, are historically known for having widespread corruption (Bakare, 2011) and structural unemployment (Kester et al., 2016). Given the data limitation with regards to many of the endogenous variables, we use a parameterisation technique, where the average of the first moment of the three economies are referred to, in parameterizing the model. The parameterisations are based primarily on official statistics obtained from the various publications of the National Bureau of Statistics of the three economies. Unless specified otherwise, all statistics are based on the average during the 2011-15 period.

On the household sector, the annual discount rate is set at 0.04 . With a 25 years structure (given that individuals live for two periods in the model), this

\footnotetext{
${ }^{20}$ While the economic structure of Nigeria depends primarily on its oil exports sector, given that the model focuses mostly on growth (and not level) of real output, we filter out the contribution of the oil sector when computing variables such as GDP growth rate and final output-to-physical capital ratio, whenever the statistics of Nigeria are referred to. However, given that the main objective is not studying a specific economy but a stylized representation of a middle-income economy with high corruption and unemployment but large infrastructure gap, this is not a huge issue that will affect the key take-aways from the policy analysis conducted.
} 
gives an intergenerational discount rate of 0.375 . The household savings rate, $\sigma$, is estimated using the household survey data, which gives an estimation of about 9.3 percent. For the time spent in tertiary education, based on a standard 3.5 years spent in the university, $\varrho=3.5 / 25=0.140$ is obtained. In terms of efficiency of training, the parameter $\chi$ is set at 0.7 , which is in between the 0.9 set by Agénor and Lim (2017) for high-income economy and the 0.5 set by Agénor and Alpaslan (2014) for the poorest low-income economy. In the absence of training cost data, the parameterised value for the skills acquisition cost (proportion to skilled wages), $\mu$, is solved for using the equation for $\theta_{t}^{U}$, written below for convenience:

$\theta^{U}=\mu^{1 / \chi}\left\{1-(1-\varrho)^{-1} \frac{\left[\zeta^{U Y}(1-\tau)+\zeta^{U L} \kappa-(1-\varrho) \zeta^{S L} \kappa\right]}{\zeta^{S Y}(1-\tau)+\zeta^{S G}}\left(\frac{\theta^{S Y}}{\left[\left(k^{G}\right)^{\varsigma_{1}^{m}}(1-\eta) \gamma\right]}\right)\right\}^{-1 / \chi}$

To solve for $\mu$, we still need the tax rate $(\tau)$, information from the intermediate goods and design sector $\left(\varsigma_{1}^{m}, \eta, \gamma\right)$, the initial values for $k^{G}$, and the relevant labour shares and probabilities. The tax rate on wages, $\tau=0.058$, is estimated by dividing the average total tax revenue as percentage of GDP (obtained from World Bank World Development Indicators) by the average labour share of the three economies. The latter is calculated based on the compensation of employees reported in the national income statistics, which yields an average of 0.28 for the three economies. This also provides the value for the elasticity of final good production to employed labour in the final good sector, $\beta=0.28$. For the rest of the production parameters in the final good sector, the elasticity parameter with respect to private capital, $\alpha$, is set at 0.35, following Agénor and Lim (2017) and within the standard range for developing economies. Constant return-to-scale assumption for the production function means $\gamma=1-\alpha-\beta=0.37$. Lastly, for the elasticity of production with respect to the public-private capital ratio, $\omega$ is set at 0.173 , in line with the meta-analysis of Bom and Ligthart (2014). 
In the intermediate goods and design sector, the substitution parameter, $\eta$, is set at 0.39 , which is consistent with Lim (2018) and the non-competitive scenario examined in Sequeira (2011). For the elasticity with respect to public capital, $\varsigma_{1}^{m}$, we use the lower-range estimate of Agénor and Neanidis (2015), $\varsigma_{1}^{m}=0.10$, which is the same as the value used in Agénor and Alpaslan (2014).

Before moving on to the public sector and the unions, first, we sort out the initial steady-state values for the labour variables, especially those that are required in the calculation of $\mu$. Based on the average of the three economies, the share of unskilled workers in the population, $\theta^{U}$, is set equal to 0.847 , which is calculated by subtracting the average share of workers with postsecondary qualification. This gives $\theta^{S}=0.141$. Using the approach, the skilled, $\theta^{S L}$, and unskilled unemployment rate, $\theta^{U L}$, are calculated using the raw unemployed numbers, which gives $\theta^{S L}=0.036$ and $\theta^{U L}=0.106$, with the weighted average yielding a headline unemployment rate of 0.104 . The probability of a skilled worker getting unemployed, $\zeta_{t}^{S L}=0.255$, and the probability of an unskilled worker getting unemployed, $\zeta^{U L}=0.125$, are easily derived. After that, the share of unskilled workers hired in the private sector, $\theta^{U Y}$, and the corresponding probability, $\zeta^{U Y}$, can be calculated, where $\theta^{U Y}=$ $\theta^{U}-\theta^{U L}=0.741$, and $\zeta^{U Y}=\theta^{U Y} / \theta^{U}=0.875$. For the share of public officials, given that only NBS Nigeria publishes detailed statistics, we use Nigeria data for the parameterization. First, we know that the number of skilled civil servants at grade GL12-GL17 of Nigerian public service as at end-2015 equals 141, 515. Dividing this by the total labour force as reported by the World Bank, 59.1 million, gives $\theta^{S G}=0.0024$, and the corresponding probability, $\zeta^{S G}=0.017$. The share of skilled labour employed in the private sector, $\theta^{S Y}=$ 0.103 , and the corresponding probability, $\zeta^{S Y}=\theta^{S Y} / \theta^{S}=0.728$, can then be calculated. Lastly, the public-private capital ratio, $k^{G}$, is set at 0.16 , which corresponds to the average estimate for the non-high income, Sub-Saharan 
African economies used in Agénor and Alpaslan (2014). Given all these initial values, we can then calculate the skills acquisition cost, $\mu$, which equals to 0.229 .

In terms of the union bargaining parameters, $\xi^{U}$ and $\xi^{S}$, we rely on the estimate of Barnerjee et al. (2008) for South Africa, which documented a wage mark-up of 1.23 times. Using $(23), \xi^{U}=\xi^{S}=0.158$ are estimated. For the wage elasticities with respect to unemployment level, $\varkappa^{U}$ and $\varkappa^{S}$, we use the average elasticity estimated by Kingdon and Knight (2006), again for South Africa, and set both $\varkappa^{U}$ and $\varkappa^{S}$ to equal 0.108 .

For the remaining variables and parameters in the public sector, using personnel cost data in the Public Finance Statistics published by the NBS Nigeria, $v_{G}=0.337$ is estimated. The share of spending on public infrastructure, $v_{I}$, is obtained by dividing the average public infrastructure investment as a percentage of GDP with the total government expenditure as a percentage of GDP for the three economies, which gives $v_{I}=0.187$. The share of total social spending/benefits as a percentage of government expenditure, $v_{S}$, cannot be ascertained directly from the public finance statistics, and therefore needs to be solved for using (41). This requires us to first estimate the initial steadystate value of $\kappa$. Due to a lack of data, we set the initial parameterization at a low value of $\kappa=0.02$. To estimate for the initial share of corrupt officials, $\varepsilon$ (which is always contentious to do so), we use a combination of the numbers (proportion of civil servants declaring their assets) published in the Social Statistics Report 2016 and the 'percentage of firms making informal payments to public officials' numbers for Nigeria. The share of civil servants not declaring their assets equals 0.425, while the latter is about 0.79. Assuming that this is representative of the share of those non-declared officers who are corrupt, we estimate $\varepsilon=0.336$. In terms of the probability of being detected, $1-p$, we set $1-p=0.8$, or equivalently, $p=0.2$, in line with the average conviction 
rate of developing economies in the UN Crime Survey statistics. For the fraction of embezzled fund recoverable upon successful detection of corruption, we set $z$ to a very small value of 0.05 to reflect the weak institutional capacity typically characterising a lower-middle income economy. Given all the parameterised initial values and parameters, $v_{S}$ is estimated using (41), which gives $v_{S}=0.125$. Lastly, we still need to estimate $\phi^{\max }$ and then determine the initial steady-state value of $\phi^{*}$. Given all the calibrated parameters and initial values, we first calculate $\phi^{*}-\bar{\phi}$ using (30), which gives 0.098. Solving this simultaneously with (31), we obtain $\phi^{*}=1.246, \phi^{\max }=1.296$, and subsequently, $\bar{\phi}=1.148$.

The final output-private capital ratio, $Y / K^{P}$, is estimated using GDP and private capital stock series obtained from the Penn World Table 9, which gives an average of $Y / K^{P}=0.524$ for the three economies. This, couple with the initial steady-state value of public-private capital ratio, $k^{G}=0.16$, allows for the calculation of $\psi$, which equals 0.305. Following Agénor and Lim (2017), the blueprint-private capital stock ratio, $m$, is normalised to 0.1 , largely for convenience and the fact that this initial ratio is immaterial to the results. The public investment efficiency ratio, $\varphi_{t}$, is set equal to 0.285 , which is based on the average index score (1.14 out of 4.0) estimated by Dabla-Norris et al. (2012). Finally, the annual growth rates for final output and private capital in the initial steady state are set equal to 4.7 percent, which corresponds to the average real GDP growth rate of the sample economies (with only the non-oil sector of Nigeria being accounted for) during the period 2011-15. The parameters and the initial steady-state values are summarised in Table 2 and 3 respectively. 


\section{Policy Experiments}

We start off by considering two policy scenarios: (i) public sector downsizing (a cut in $v_{G}$ ), which is a measure that had been undertaken by various Sub-Saharan governments before, such as the Obasanjo government in Nigeria in the late 1990s (Kester et al., 2016); and (ii) an attempt to raise the minimum income by increasing the endogenous social security/benefit rate, $\kappa_{t}$, which can be achieved by increasing the share of spending in social security/benefits in the budget, $v_{S}$. The latter, when simulated together with a training cost cut, $\mu$, allows for potentially achieving a simultaneous goal of job creation/unemployment reduction: the policy goal of many African middleincome economies, including the three referred to in our parameterization. In addition, we also consider a scenario where there is a reduction in the unskilled workers' union mark-up, which is usually a popular policy means in the labour market reform literature to be used in increasing the absorption of unskilled workers into the workforce.

After that, we simulate a conventional public infrastructure-push policy scenario by increasing $v_{I}$. To preview, readers experienced in economic dynamics would notice from the Appendix that, in a corruption model with leakages such as this (where the actual quality does not depend on 'on-paper' reported expenditure), the parameter $v_{I}$ is policy-neutral and does not appear anywhere in the difference equation system, saved for the public investment efficiency index, $\varphi_{t}$. To overcome this characteristic of the benchmark solution, we examine a policy scenario with endogenous threshold and switching. Specifically, assuming a policy scenario where after a period of ambitious anticorruption reform reducing the corruption rate, $\varepsilon_{t}$, to below a certain threshold level, the dynamics of the system would then change, in which equation (39) is replaced by (36). This may be interpreted as the government successfully reducing the corruption rate to a negligible level, hence closing the reporting 
gap between actual and reported expenditure on public capital.

As mentioned, for all the experiments, in addition to the benchmark case, we also consider sensitivity analysis cases where there is (i) endogenous $\psi_{t}$; (ii) evolving probability $p$ over time, by virtue of the one-to-one relationship with monitoring intensity ${ }^{21}$; and (iii) a linear specification for the concealment cost (elasticity parameter, $\delta=1.0$ ), which also implies a stronger relationship between the unemployment rates and the concealment cost. All the policy shocks considered are permanent and their impact is measured in terms of a few key variables - the public investment efficiency index, the corruption rate, the unemployment rates, the size of the public sector employment, and the growth rate of the final output. Unless specified otherwise, all policy experimented involves a 10 percent increase/decrease. All the simulation results (impact and steady-state effects) are summarised in Tables 4-7, with the transitional dynamics associated with selected policy experiments presented in Figures 1$4 .^{22}$

\subsection{Public Sector Downsizing}

First, consider a 10 percent cut in the share of spending on public emoluments, $v_{G}$, where the saved amount gets reallocated to other non-directly productive expenditure component, $v_{O}$. Both the impact and steady-state effects are pre-

\footnotetext{
${ }^{21} \mathrm{~A}$ common specification used in the development economics literature to model gradual evolution involves assuming $p$ to evolve according to $p_{t}=\left(p_{t-1}\right)^{\mu_{P}}\left(p_{m} \frac{\bar{N}}{\varepsilon_{t} N_{t}^{S G}}\right)^{1-\mu_{P}}$, where $\mu_{P}$, set equal to 0.8 here, essentially means a high persistence for $p$. However, in consistent with studies such as Haque and Kneller (2015), we assume that it gets easier for the government to detect corruption the larger the share of corrupt officials becomes in the population.

${ }^{22}$ Similar to Agénor and Alpaslan (2014), Agénor and Lim (2017), and other models examining transitional dynamics in the literature, there is a distinction between generational periods $(T)$ and simulated period $(t)$. In principle, $T$ corresponds to 25 years in a two-periods lived structure, as reflected in the discount factor and the assumption of full depreciation of physical capital. However, all of the other parameters and variables either do not have a time dimension or are calibrated on the basis of average annual data. For the numerical experiments, the intended length of a unit of time interval is therefore $t=1 / 25$, or best understood as one year.
} 
sented in Table 4, with the transitional dynamics of key variables illustrated in Figure 1. From (38), we see that a $v_{G}$ cut has a direct downward shift effect on the effective share of public officials, $\theta_{t}^{S G}$, in the economy. Given initial fixed amount of effective skilled labour, $\theta_{t}^{S}$, and those employed in the private sector, $\theta_{t}^{S Y}$, this means there is a corresponding increase in skilled unemployment, $\theta_{t}^{S L}$, on impact. On the surface, by virtue of the specification of (29), the intended aim of such a policy intervention may be to provide an uemployment-as-disciplinary, corruption-prevention incentive for the public officials, at the cost of a slight increase in skilled unemployment. However, in this model where public spending on emoluments have productive implications (despite the possibility of corruption) and there are richer feedback mechanisms, the general equilibrium effects of public sector workforce downsizing actually leads to more corruption in the economy. First, given that the non-tax deductible skilled wage of a public official represents the best job possibility for a skilled worker, the fall in the probability of a skilled worker getting employed as a public official means a decline in the expected skilled wages. This results in a disincentive for skills acquisition in the economy, which is reflected in the increase (decrease) in the share of unskilled (skilled) workers. This larger unskilled workforce then has a proportionate impact on the unskilled unemployment rate.

At the same time, in the public sector, less number of public officials means, given fixed units of public capital goods demanded in each period, $g_{t}$, each remaining public official is now in-charged of procuring more. This gives more potential room for the inflating of procurement cost, or mathematically, translates to a larger gap between the incentive for corruption threshold, $\phi_{t}^{*}$, and the maximum-reportable $\phi^{\max }$. Indeed, this direct effect dominates the effect of the unemployment ratio has on the concealment cost. For any given number of public officials that remains employed by the public sector, the share of those 
corrupt officials therefore rises. There is then a wider gap between the actual and reported expenses, hence translating to a decline in public investment efficiency.

Over the long-run, for a given $g_{t} / N_{t}^{S G}$ unit of procurement responsibility, smaller $N_{t}^{S G}$ translates to an overall smaller $g_{t}$, which implies a smaller public-to-private capital ratio in the economy. In the steady state, this is slightly detrimental to growth - a decline in final output growth rate in the order of -0.14 percentage points. In terms of the labour market, in the steady state, the level effect associated with the overall drop in the total pool of skilled workers eventually overwrite the positive impact of skilled unemployment rate, resulting in a steady-state net decline in $\theta_{t}^{S L}$ in the order of -0.03 percentage points. The overall impact on the headline unemployment rate is mildly positive, due to a larger steady-state increase in the unskilled unemployment rate. In terms of the public sector, in the steady state, the corruption rate, $\varepsilon_{t}$, ends up 7 percentage points higher, despite a smaller share of public officials in the economy. This, coupled with the -0.6 percentage points change in public investment efficiency and negative output growth rate, means a vanilla public sector downsizing strategy can be detrimental to such an economy. Indeed, it can be argued that the steady-state policy effects of an increase in the headline unemployment rate, a decrease in public investment efficiency, an increase in the economywide corruption rate, and a slightly negative growth effects are largely consistent with the economic performance observed during the infamous public sector downsizing era of the Obasanjo government, as described by Kester et al. (2016). Both Table 4 and Figure 1 also illustrate the policy effects under the other three sensitivity scenarios, which present largely similar policy dynamics to the benchmark case (in the case with endogenous $\psi_{t}$, the generated solutions are much more unstable, though the overall transitional paths remain consistent). 
In Table 4, we also consider an alternative scenario where the saved expenses from a $v_{G}$ cut is reallocated instead to social spending, $v_{S}$. Overall, we see that the effects are not much different from those observed in the previous scenario, only that the disincentive effect on skills acquisition becomes smaller (the cost associated with becoming unemployed after acquiring skills [arisen from the retrenching public officials] is marginally smaller, given that the level of unemployment benefits received for the skilled unemployed is higher in this scenario), with skills unemployment rate remains positive even in the long-run. The steady-state corruption rate is also slightly lower, though the negative growth effect becomes relatively larger due to overall lower level of production in the economy. This also suggests that the general equilibrium effects associated with a $v_{G}$ cut is likely to dominate those associated with the $v_{S}$ rise, which is examined next.

\subsection{Raising Minimum Income and Training}

This policy experiment can be interpreted in the context of Nigerian President Buhari's recent Social Intervention Scheme (SIS), which has the intention of creating more jobs, while simultaneously raising the minimum income of the population. In the context of this model, we start by considering a plain 10 percent increase in the share of social security/benefit spending, $v_{S}$, financed by a reallocation from other non-directly productive spending, $v_{O}$. The results are illustrated in both Table 5 and Figure 2. Compared to the previous scenario where such a scheme is financed by a cut in emoluments, the overall policy effects are much improved.

In the context of the overall system, an increase in $v_{S}$, ceteris paribus, leads to a larger indexation rate, $\kappa_{t}$. This means the minimal income in the economy, $b_{t}$, for a given level of per capita income, increases. This results in the increase in both the expected skilled wage and the expected unskilled wage, though the 
effect on the former tends to be slightly larger (by virtue of the level, $w_{t}^{S}>$ $\left.w_{t}^{U}\right)$. This therefore creates a net positive skills acquisition incentive (level effect), resulting in the overall expansion of skilled workforce in the economy. Nevertheless, in terms of reallocation effect, this policy predictably, does badly in combatting unemployment, as both the skilled and unemployment rates go up - the former increases 0.3 percentage points in the steady state, while the latter by 0.8 percentage points. The level of employment in the private sector for both types of workers is lower, resulting in lower production and a negative impact effect on real output growth, in the order of -0.1 percentage points in the steady state.

Nevertheless, instead of labelling such a policy as ineffective in typical classical economic interpretation, this policy does have its merits in an economy with corruption. Overall, the net effect or the change in unemployment ratio, $\theta_{t}^{S L} / \theta_{t}^{U L}$, is positive (by virtue of the initial level of skilled unemployment being lower). From (29), this means the impact on concealment cost is higher, as the uemployment-as-disciplinary, corruption-prevention incentive is in action here. For any given cost associated with public procurement, the required mark-up (inflated cost) for any official to corrupt becomes higher. Specifically, the incentive for corruption threshold, $\phi_{t}^{*}$, becomes larger, which in turns results in a smaller gap between $\phi_{t}^{*}$ and $\phi^{\max }$. In the steady state, the share of corrupt officials therefore falls by 0.6 percentage points.

Indeed, the conventional argument for the use of minimum wage and unemployment benefit provision tend to focus on their potential effects in incentivising the poor to accumulate human capital. In other words, if such a policy is associated with a simultaneous reduction in the skills acquisition cost in the economy, then the economic implications are good. A crude experiment to examine this involves simulating an increase in $v_{S}$ and $\mu$ each by 10 percent, financed by a 20 percent cut in $v_{O}$, as also shown in Table 
5. The skills expansion effect is predictably larger, which is associated with a smaller deviation in unskilled unemployment rate (by implications, the overall headline unemployment rate), though still positive, and more importantly, a positive steady-state effect on real output growth rate. While this scenario does result in a by-product of a slightly larger skilled unemployment rate, this is warranted as, along with higher expected skills wage premium, it provides a stronger corruption-prevention incentive, which in steady state, translates to a -9 percentage point change in the share of corrupt officials. In others words, the share of corrupt officials declines from the initial 33.6 percent of total public officials to 24.6 percent. This decline in corruption, together with the positive growth effect associated with skills expansion, leads to an improved public investment efficiency ratio by 0.4 percentage points.

\subsection{Ambitious Social Reform Programme}

As seen in the previous experiments, there is some merits in using a minimum income/wage strategy in addressing corruption in a developing economy. However, any ambitious social reform programme must necessarily also aim to reduce the headline total unemployment rate. In the model context, a policy that can achieve a reduction in unskilled unemployment rate is through union reform - one of the labour market reform policies found by Bernal-Verdugo et al. (2012) to be effective in reducing unemployment for their non-OECD country sample. More specifically, consider a 10 percent reduction in the parameter $\xi^{U}$, which governs the mark-up over the target wage for the unskilled workers, as seen in (23). In a non-technical context, within such a model where there is no explicit distinction between participation rate, this may be interpreted as a policy designed to bring more unskilled workers into the employed labour force. The results of this individual policy are summarised in Table 6, with the transitional dynamics presented in Figure 3. In all four 
cases analysed, the steady-state effect on unskilled unemployment rate is consistently negative. While the effects on growth and skilled unemployment rate are marginally lower and higher respectively, this individual policy provides another useful tool in tackling corruption while simultaneously reducing the headline unemployment rate.

Next, we consider an ambitious composite reform programme. Specifically, we consider an increase in $v_{S}$ by 10 percent, a training cost cut, $\mu$, by 20 percent, and a reduction in $\xi^{U}$ by 20 percent (which translates to 1.17 times of mark-up), with both the impact and steady-state results also presented in Table 6. In the steady-state, we see that there is a robust increase in the effective share of skilled labour by 1.3 percentage points, a decline in headline unemployment rate in the order of -0.4 percentage points, and a positive growth effect of 0.27 percentage points. However, the absolute deviation of public investment efficiency index remains negative, and the skilled unemployment rate increases by 1.2 percentage points. With the policy tool of public infrastructure investment share, $v_{I}$, being irrelevant in this dynamic system, there is no room for the use of a conventional infrastructure-push policy to address these two shortcomings. Nonetheless, in the benchmark case, the programme is very effective in reducing the public sector corruption rate, with the benchmark case registering a steady-state deviation of the order -25.9 percentage points, or equivalently, reducing corruption rate to only 7.6 percent of the total public officials in the economy. Indeed, at some point along the transition, corruption rate is reduced to an insignificant level, which paves the way for a subsequent examination of an endogenous threshold-induced structural change. 


\subsection{Public Investment in Infrastructure}

As documented in Agénor (2012) and Agénor and Lim (2017), public investment in infrastructure, through its productivity-enhancing supply-side effects, can be a powerful tool in raising final output growth while addressing the persistent absorption/skilled unemployment issue associated with a skills expansion policy. However, in a corruption-based model such as this where there is a difference between actual and reported public investment expenses, a measure such as $v_{I}$ can become impotent (as seen in Table 7). Nevertheless, a conceptually plausible composite reform strategy is to first push the corruption rate in the economy down to an insignificant level, after which the government will be able to wipe out corruption and close the quality-reporting gap associated with public investment. After that, $v_{I}$ can become a viable policy tool. Specifically, we introduce a regime-switching approach based on an endogenous threshold of (insignificant) corruption level, $\hat{\varepsilon}=0.03$, below which then a regime-switch is triggered and the dynamics are then driven by a different system. ${ }^{23}$ Specifically, the new system is derived and can be referred to in the Appendix [equations (A40a) to (A40m)], which is clearly independent of $\varepsilon_{t}$ and $\phi$. In terms of the public capital, given that there is no more leakage in the new regime, (33) is no longer applicable, and the budgetary version of (36) ought to be used in place of $G_{t}^{I}$.

For all four cases studied (benchmark, plus the other three sensitivity analysis cases), we introduce this endogenous switching condition and examine again, the ambitious composite reform programme, plus an increase in $v_{I}$ also by 10 percent. The experiment results are summarised in Table 7, with transitional dynamics presented in Figure 4. Of the four cases studied, only

\footnotetext{
${ }^{23}$ An arbitrarily low corruption rate of $\hat{\varepsilon}=0.03$ is set as what we deemed as insignificant rate of corruption that will trigger a regime-switch and therefore structural change in the economy. This is due to the technicality that the "corner solution" with $\varepsilon_{t}=0$ does not exist for the benchmark system, which is only solvable when interior solutions exist.
} 
the benchmark model triggers the regime-switch when corruption rate drops below its threshold, $\hat{\varepsilon}=0.03$, in period $t=4$. As such, there is a structural change induced. For the dynamics illustrated in Figure 4, save for the line labelled 'Benchmark (with switching)' and the graph for public investment efficiency, the other four represent exactly the same transitional dynamics that we would have observed for the composite programme examined earlier (given the irrelevance of $v_{I}$ prior to switching).

Comparing the benchmark case with and without regime-switching taking place, we see that the subsequent introduction of $v_{I}$ results in final output growth rate to be at +0.4 percentage points at end-steady state. This is due to the huge gain in public investment efficiency as a result of the structural change. The increase in skilled unemployment rate has also become much more manageable. Nonetheless, the policy effects on reducing unskilled and headline unemployment rate has become not as effective in such a hypothetical corruption-free economy. These results provide interesting food-for-thought on whether social policies designed to reduce unemployment rate would work as well in a zero-corruption economy, especially given the existence of the dynamic tradeoff between skilled unemployment and corruption. Nevertheless, the results from the regime-switching exercise suggests a role for the seemingly (and usually classified as) unproductive social spending in promoting structural change in a corruption-heavy developing economy, before the implementation of a standard 'large-scale' public infrastructure push - an observation not previously documented in the literature.

\section{Concluding Remarks}

This article presents a dynamic endogenous growth model with heterogeneous labour, endogenous unemployment and public sector corruption to address four shortcomings in the existing literature on macroeconomics of corruption. Un- 
like previous studies, the model does not separate public officials and private individuals into two distinct groups. Instead, taking up bureaucratic appointment as a public servant is modelled as an occupational choice, which then allows for the endogenous determination of all three variables of the proportion of public officials, the share of corrupt officials among them, and the public investment efficiency within a dynamic system. Parameterised for a stylized representation of a typical middle-income African economies with the 'twinhigh' problem of corruption and unemployment, the dynamics of endogenous corruption and unemployment, as well as their policy tradeoff, are studied using simulated policy experiments, ranging from public sector downsizing, social intervention scheme, to an ambitious social reform programme preceding a push in public infrastructure investment. The novel contributions of the study are summarised in the introduction and need not be repeated here. We therefore focus on potential extensions that can be pursued in future research.

The dynamic relationship between unemployment and corruption in this model depends critically on the specification of the concealment cost function. While sensitivity analysis results seem to suggest that functional specification does not significantly affect the results, the validity of the Shapiro-Stiglitz type of uemployment-as-disciplinary mechanism does play a significant role in shaping the unemployment-corruption nexus in this model. While there are empirical studies documenting this relationship, such as Bouzid (2016), the empirical validity remains limited. As such, for future studies, a rigorous empirical examination based on a more parsimonious version of this model is warranted. In terms of theoretical extension, the model can be extended to account for other forms of public sector corruption, notably those associated with tax collection. That will then enable more detailed examinations of the tax implications, which is a feature largely simplified in this model. In addition, many African economies have a sizeable oil or natural resource sector, 
including Nigeria, of which this study has largely abbreviated. This is done as a self-contained measure, as adding a largely exogenous oil sector will have no effect on any policy direction observed with the policy experiments implemented. For future study, a more sophisticated model with greater emphasis on the natural resources sector is definitely worth-exploring. 


\section{References}

Acemoglu, D. and T. Verdier (1998) 'Property Rights, Corruption and the Allocation of Talent: A General Equilibrium Approach', Economic Journal, 108: 1381-403.

Agénor, PR (2012) Public Capital, Growth and Welfare, New Jersey: Princeton University Press.

Agénor, PR (2016) 'Aid Volatility, Human Capital, and Growth', Working Paper No. 219, Centre for Growth and Business Cycle Research, University of Manchester.

Agénor, PR and B. Alpaslan (2014) 'Infrastructure and Industrial Development with Endogenous Skill Acquisition', Working Paper No. 195, Centre for Growth and Business Cycle Research, University of Manchester.

Agénor, PR and O. Canuto (2015) 'Middle-Income Growth Traps', Research in Economics, 69: 641-60.

Agénor, PR and O. Canuto (2017) 'Access to Finance, Product Innovation and Middle-income Traps', Research in Economics, 71: 337-55.

Agénor, PR and K.Y. Lim (2017) 'Unemployment, Growth and Welfare Effects of Labour Market Reforms', Working Paper No. 232, Centre for Growth and Business Cycle Research, University of Manchester.

Agénor, PR, M. Nabli, T. Yousef and H.T. Jensen (2007) 'Labor Market Reforms, Growth, and Unemployment in Labor-Exporting Countries in the Middle East and North Africa', Journal of Policy Modeling, 29: 277-309.

Agénor, PR, and K. Neanidis (2015) 'Innovation, Public Capital, and Growth', Journal of Macroeconomics, 44: 252-75.

Anand, R. and P. Khera (2016) 'Macroeconomic Impact of Product and Labor Market Reforms on Informality and Unemployment in India', IMF Working Paper No. 16/47, International Monetary Fund.

Bakare, A. S. (2011) 'The Crowding-Out Effects of Corruption in Nigeria: An Empirical Study', Journal of Business Management and Economics, 2: 59-68.

Banerjee, A. (1997) 'A Theory of Misgovernance', Quarterly Journal of Economics, 112: 1289-332.

Banerjee, A., S. Galiani, J. Levinsohn, Z. McLaren and I. Woolard (2008) 'Why has Unemployment Risen in the New South Africa?', Economics of Transition, 16: $715-40$.

Bernal-Verdugo, L., D. Furceri and D. M. Guillaume (2012) 'Labor Market Flexibility and Unemployment: New Empirical Evidence of Static and Dynamic Effects', Comparative Economic Studies, 54: 251-73. 
Bhattacharyya, C., and M. R. Gupta (2015) 'Unionised Labour Market, Unemployment Allowances, Productive Public Expenditure and Endogenous Economic Growth', Metroeconomica, 66: 397-425.

Blackburn, K. and G. F. Forgues-Puccio (2009) 'Why is Corruption Less Harmful in Some Countries than in Others', Journal of Economic Behavior $\mathcal{E}$ Organization, 72: 797-810.

Blackburn, K. (2010) 'Endogenous Corruption in Economic Development', Journal of Economic Studies, 37: 4-25.

Blackburn, K., N. Bose and M. E. Haque (2011) 'Public Expenditure, Bureaucratic Corruption and Economic Development', Manchester School, 79: 405-28.

Bom, P. R. and J. E. Ligthart (2014) 'What Have We Learned from Three Decades of Research on the Productivity of Public Capital?', Journal of Economic Surveys, 28: 889-916.

Bose, N., S. Capasso and A. P. Murshid (2008) 'Threshold Effects of Corruption: Theory and Evidence', World Development, 36: 1173-91.

Bouzid, B. N. (2016) 'Dynamic Relationship between Corruption and Youth Unemployment', Policy Research Working Paper No. 7842, Washington DC: World Bank.

Chakraborty, S. and E. Dabla-Norris (2011) 'The Quality of Public Investment', B.E. Journal of Macroeconomics, 11: 1-29.

Cule, M. and M. Fulton (2005) 'Some Implications of the Unofficial EconomyBureaucratic Corruption Relationship in Transition Countries', Economic Letters, 89: 207-11.

Dabla-Norris, E., J. Brumby, A. Kyobe, Z. Mills and C. Papageorgiou (2012) 'Investing in Public Investment: An Index of Public Investment Efficiency', Journal of Economic Growth, 17: 235-66.

Delavallade, C. (2006) 'Corruption and Distribution of Public Spending in Developing Countries', Journal of Economics and Finance, 30: 222-39.

Del Monte, A. and E. Papagni (2001) 'Public Expenditure, Corruption, and Economic Growth: The case of Italy', European Journal of Political Economy, 17: $1-16$.

Dzhumashev, R. (2014) 'The Two-way Relationship between Government Spending and Corruption and its Effects on Economic Growth', Contemporary Economic Policy, 32: 403-19.

Dzhumashev, R. (2016) 'The Role of Income Uncertainty in the CorruptionGrowth Nexus', B.E. Journal of Economic Analysis 83 Policy, 16: 1169-201.

Dinopoulos, E. and P. S. Segerstrom (1999) 'A Schumpeterian Model of Protection and Relative Wages', American Economic Review, 89: 450-72.

Ehrlich, I. and F. T. Lui (1999) 'Bureaucratic Corruption and Endogenous Economic Growth', Journal of Political Economy, 107: 270-93. 
Fredriksson, A. (2010) 'Bureaucracy Intermediaries, Corruption and Red Tape', Journal of Development Economics, 108: 107-14.

Galor, O. and O. Moav (2000) 'Ability biased technological transition, wage inequality and growth', Quarterly Journal of Economics, 115: 469-98.

Guriev, S. (2004) 'Red Tape and Corruption', Journal of Development Economics, 73: 489-504.

Haque, M. E., and R. Kneller (2015) 'Why Does Public Investment Fail to Raise Economic Growth? The Role of Corruption', Manchester School, 83: 623-51.

Heer, B., and A. Morgenstern (2005) 'The Labor Market Effects of Indexing Unemployment Benefits to Previous Earnings', Public Finance Review, 33: 385-402.

Infante, D. and J. Smirnova (2009) 'Rent-Seeking Under A Weak Institutional Environment', Economic Letters, 104: 118-21.

Jones, C. I. (2005) 'Growth and Ideas', in Handbook of Economic Growth, ed. by P. Aghion and S. Durlauf, Elsevier, 1B, 1063-111.

Lackó, M. (2004) 'Tax Rates and Corruption: Labour-market and Fiscal Effects', Research Reports No. 309, Vienna Institute for International Economic Studies.

Lim, K.Y. (2018) 'Industrial Transformation with Heterogeneous Labor and Foreign Experts', Macroeconomic Dynamics, First View.

Kester, K.O, A. R. Bankole, and O.S. Samuel (2016) 'The Trade Union Movement and the Challenges of Economic Reforms in the Emerging Nigerian Economy', in Reforms and Nigerian Labour and Employment Relations: Perspectives, Issues and Challenges, ed. by D. Otobo, Chapter 12, Malthouse Press.

Kingdon, G. and J. Knight (2006) 'How Flexible Are Wages in Response to Local Unemployment in South Africa?', ILR Review, 59: 471-95.

Lui, F. T. (1986) 'A Dynamic Model of Corruption Deterrence', Journal of Public Economics, 31: 215-36.

Mauro, P. (1997) 'The Effects of Corruption on Growth, Investment and Government Expenditure: A Cross-Country Analysis', in Corruption and the Global Economy, ed. by K. A. Elliott, Institute for International Economics.

Méndez, F. and F. Sepúlveda (2006) 'Corruption, Growth and Political Regimes: Cross Country Evidence', European Journal of Political Economy, 22: 82-98.

Ndikumana, L (2006) 'Corruption and Pro-Poor Growth Outcomes: Evidence and Lessons for African Countries', Working Paper No. 120, Political Economy Research Institute.

Rajkumar, A. S., and V. Swaroop (2008) 'Public spending and outcomes: Does governance matter?' Journal of Development Economics, 86: 96-111.

Ryvkin, D. and D. Serra (2012) 'How Corruptible Are You? Bribery Under Uncertainty', Journal of Economic Behavior \& Organization, 81: 466-77. 
Sarte, PD (2000) 'Informality and Rent-Seeking Bureaucracies in a Model of Long-run Growth', Journal of Monetary Economics, 46: 173-97.

Sequeira, T. (2011) 'R\&D Spillovers In An Endogenous Growth Model With Physical Capital, Human Capital, And Varieties', Macroeconomic Dynamics, 15: 223-39.

Spinesi, L. (2009) 'Rent-Seeking Bureaucracies, Inequality, and Growth', Journal of Development Economics, 90: 244-57.

Tanaka, H., and T. Iwaisako (2009) 'Product cycles, endogenous skill acquisition, and wage inequality', Canadian Journal of Economics, 42: 300-31.

Van Schaik, A., and H. de Groot (2000) 'Unemployment, Growth and Efficiency Wages', in Growth, Unemployment and Deindustrialization, ed. by H. de Groot, Cheltenham: Edward Elgar.

World Bank (2012) World Development Report 2013: Jobs. Washington DC: World Bank. 
Table 1

Variables and their Different Outcome in the Model's Public Capital Good Procurement Framework

\begin{tabular}{lcc}
\hline \multicolumn{1}{c}{ Variable } & High-quality & Low-quality \\
\hline Unit of quality purchased & 1 & $\Upsilon<1$ \\
\hline Raw unit of quantity purchased & $\frac{g_{t}}{N_{t}^{S G}}$ & $\frac{g_{t}}{N_{t}^{S G}}$ \\
\hline Unit of quality-adjusted purchase & $\frac{g_{t}}{N_{t}^{S G}}$ & $\Upsilon\left[\frac{g_{t}}{N_{t}^{S G}}\right]$ \\
\hline Actual cost/spending incurred & Drawn from & 1 \\
& $\phi_{t} \in\left(1, \phi^{\max }\right)$ & \\
\hline Claimed/reported cost/spending & Drawn from & 1 \\
by a non-corrupt official & $\phi_{t} \in\left(1, \phi^{\max }\right)$ & \\
\hline Claimed/reported cost/spending & Drawn from & Drawn from \\
by a corrupt official & $\phi_{t} \in\left(\bar{\phi}, \phi^{\max }\right)$ & $\phi_{t} \in\left(\bar{\phi}, \phi^{\max }\right)$ \\
\hline \hline
\end{tabular}


Table 2

Parameter Values: Benchmark Case

\begin{tabular}{|c|c|c|}
\hline Parameter & Description & Value \\
\hline \multicolumn{3}{|c|}{ Households } \\
\hline$\rho$ & Intergenerational discount rate & 0.375 \\
\hline$\sigma$ & Household savings rate & 0.093 \\
\hline$\chi$ & Training productivity parameter & 0.7 \\
\hline$\mu$ & Skills acquisition cost & 0.229 \\
\hline$\varrho$ & Time allocated to university & 0.140 \\
\hline \multicolumn{3}{|c|}{ Private sector production } \\
\hline$\omega$ & FG elasticity wrt public-private capital ratio & 0.173 \\
\hline$\beta$ & FG elasticity wrt unskilled workers & 0.28 \\
\hline$\alpha$ & FG elasticity wrt private capital & 0.35 \\
\hline$\gamma$ & FG elasticity wrt intermediate input & 0.37 \\
\hline$\eta$ & Substitution parameter, intermediate goods & 0.39 \\
\hline$\varsigma_{1}^{m}$ & Blueprint elasticity wrt public services & 0.100 \\
\hline \multicolumn{3}{|c|}{ Public sector } \\
\hline$\tau$ & Tax rate on total wages & 0.058 \\
\hline$v_{I}$ & Share of spending on infrastructure & 0.187 \\
\hline$v_{G}$ & Share of spending on public emoluments & 0.337 \\
\hline$v_{S}$ & Share of spending on social security/benefits & 0.125 \\
\hline$\Upsilon$ & Sub-quality public capital good purchase & 0.7 \\
\hline$\delta$ & Elasticity parameter, concealment cost & 0.5 \\
\hline$p$ & Probability of avoiding detection & 0.8 \\
\hline$\phi^{\max }$ & Upper bound, cost for inflated reporting & 1.296 \\
\hline$\psi$ & Ratio of capital goods demanded by government & 0.305 \\
\hline$z$ & Fraction of embezzled funds recovered & 0.05 \\
\hline \multicolumn{3}{|c|}{ Labour union } \\
\hline$\xi^{U}$ & Relative weight, unskilled workers & 0.158 \\
\hline$\xi^{S}$ & Relative weight, skilled workers & 0.158 \\
\hline$\varkappa^{U}$ & Elasticity wrt unemployment, unskilled wage & 0.108 \\
\hline$\varkappa^{S}$ & Elasticity wrt unemployment, skilled wage & 0.108 \\
\hline
\end{tabular}


Table 3

Initial Steady-State Values of Key Variables

\begin{tabular}{clc}
\hline \hline Variable & \multicolumn{1}{c}{ Description } & Value \\
\hline \hline$\theta^{U}$ & Share of unskilled workers in population & 0.847 \\
$\theta^{S}$ & Share of effective skilled workers in population & 0.141 \\
$\theta^{S G}$ & Share of (effective skilled) public officials & 0.002 \\
$\theta^{S Y}$ & Share of effective skilled workers in private sector & 0.103 \\
$\theta^{S L}$ & Skilled unemployment rate & 0.036 \\
$\theta^{U Y}$ & Share of unskilled workers in private sector & 0.741 \\
$\theta^{U L}$ & Unskilled unemployment rate & 0.106 \\
$\zeta^{S G}$ & Prob. of skilled workers employed in public sector & 0.017 \\
$\zeta^{S Y}$ & Prob. of skilled workers employed in private sector & 0.728 \\
$\zeta^{S L}$ & Prob. of skilled workers getting unemployed & 0.255 \\
$\zeta^{U Y}$ & Prob. of unskilled workers getting employed & 0.875 \\
$\zeta^{U L}$ & Prob. of unskilled workers getting unemployed & 0.125 \\
$\varepsilon$ & Corruption rate & 0.336 \\
$\kappa$ & Social security/benefit rate, to per capita income & 0.020 \\
$k^{G}$ & Public-private capital ratio & 0.160 \\
$Y / K^{P}$ & Final output-private capital ratio & 0.524 \\
$m$ & Blueprint-private capital stock ratio & 0.100 \\
$\phi^{*}$ & Optimal threshold cost for inflated reporting & 1.246 \\
$\varphi_{t}$ & Public investment efficiency & 0.285 \\
\hline \hline
\end{tabular}


Table 4

Policy Experiment Results for (i) Public Sector Downsizing, and (ii) Public Sector Downsizing, but with reallocation to Social Security Spending

Public Sector Downsizing: ${ }^{a}$

Share of unskilled workers

Effective share of skilled workers

Effective share of public officials

Skilled unemployment rate

Unskilled unemployment rate

Headline unemployment rate

Share of corrupt officials

Social Security/Benefit rate

Growth rate of final output

Public investment efficiency

Public Sector Downsizing, with Reallocation to

Social Security/Benefit Spending: ${ }^{\text {b }}$

Share of unskilled workers

Effective share of skilled workers

Effective share of public officials

Skilled unemployment rate

Unskilled unemployment rate

Headline unemployment rate

Share of corrupt officials

Social Security/Benefit rate

Growth rate of final output

Public investment efficiency

\begin{tabular}{|c|c|c|c|c|c|c|c|c|}
\hline \multirow{3}{*}{ Baseline } & \multicolumn{8}{|c|}{ Absolute Deviations from Baseline } \\
\hline & \multicolumn{2}{|c|}{ Benchmark } & \multicolumn{2}{|c|}{ Endogenous $\psi$} & \multicolumn{2}{|c|}{ Endogenous $p$} & \multicolumn{2}{|c|}{$\delta=1.0$} \\
\hline & Impact & Steady-state & Impact & Steady-state & Impact & Steady-state & Impact & Steady-state \\
\hline 0.847 & 0.000 & 0.002 & 0.000 & 0.001 & 0.000 & 0.001 & 0.000 & 0.002 \\
\hline 0.141 & 0.000 & -0.002 & 0.000 & -0.001 & 0.000 & -0.001 & 0.000 & -0.002 \\
\hline 0.002 & 0.000 & 0.000 & 0.000 & 0.000 & 0.000 & 0.000 & 0.000 & 0.000 \\
\hline 0.036 & 0.000 & 0.000 & 0.000 & 0.000 & 0.000 & 0.000 & 0.000 & -0.001 \\
\hline 0.106 & 0.000 & 0.001 & 0.000 & 0.000 & 0.000 & 0.000 & 0.000 & 0.000 \\
\hline 0.104 & 0.000 & 0.001 & 0.000 & 0.000 & 0.000 & 0.000 & 0.000 & 0.000 \\
\hline 0.336 & 0.062 & 0.069 & 0.062 & 0.045 & 0.055 & 0.048 & 0.045 & 0.050 \\
\hline 0.020 & 0.000 & 0.000 & 0.000 & 0.000 & 0.000 & 0.000 & 0.000 & 0.000 \\
\hline 0.047 & 0.000 & -0.001 & 0.000 & -0.001 & 0.000 & -0.001 & 0.000 & -0.002 \\
\hline 0.285 & -0.007 & -0.006 & -0.007 & -0.018 & -0.006 & -0.007 & -0.004 & -0.004 \\
\hline \multirow{3}{*}{ Baseline } & \multicolumn{8}{|c|}{ Absolute Deviations from Baseline } \\
\hline & \multicolumn{2}{|c|}{ Benchmark } & \multicolumn{2}{|c|}{ Endogenous $\psi$} & \multicolumn{2}{|c|}{ Endogenous $p$} & \multicolumn{2}{|c|}{$\delta=1.0$} \\
\hline & Impact & Steady-state & Impact & Steady-state & Impact & Steady-state & Impact & Steady-state \\
\hline 0.847 & 0.000 & 0.000 & 0.000 & -0.001 & 0.000 & 0.000 & 0.000 & 0.000 \\
\hline 0.141 & 0.000 & 0.000 & 0.000 & 0.001 & 0.000 & 0.000 & 0.000 & 0.000 \\
\hline 0.002 & 0.000 & 0.000 & 0.000 & 0.000 & 0.000 & 0.000 & 0.000 & 0.000 \\
\hline 0.036 & 0.001 & 0.003 & 0.001 & 0.003 & 0.001 & 0.003 & 0.001 & 0.002 \\
\hline 0.106 & 0.003 & 0.009 & 0.003 & 0.008 & 0.003 & 0.008 & 0.002 & 0.008 \\
\hline 0.104 & 0.003 & 0.008 & 0.003 & 0.008 & 0.002 & 0.008 & 0.002 & 0.008 \\
\hline 0.336 & 0.059 & 0.064 & 0.060 & 0.042 & 0.053 & 0.049 & 0.044 & 0.047 \\
\hline 0.020 & 0.002 & 0.000 & 0.002 & 0.000 & 0.002 & 0.000 & 0.001 & 0.000 \\
\hline 0.047 & -0.002 & -0.002 & -0.002 & -0.001 & -0.002 & -0.002 & -0.002 & -0.002 \\
\hline 0.285 & -0.007 & -0.006 & -0.007 & -0.014 & -0.006 & -0.005 & -0.004 & -0.003 \\
\hline
\end{tabular}

a/ $A$ reduction in $v_{G}$ by 10 percent.

$\mathrm{b} / \mathrm{A}$ reduction in $\mathrm{v}_{\mathrm{G}}$ by 10 percent, leading to an increase in $\mathrm{v}_{\mathrm{S}}$ by 10 percent.

Source: Authors' calculations. 
Table 5

Policy Experiment Results for (i) Raising Social Security/Benefit Spending, and (ii) Raising Social Security/Benefit Spending, plus a reduction in training cost, both financed by a reallocation from other non-directly productive public spending

Raising Social Security/Benefit Spending: ${ }^{c}$

Share of unskilled workers

Effective share of skilled workers

Effective share of public officials

Skilled unemployment rate

Unskilled unemployment rate

Headline unemployment rate

Share of corrupt officials

Social Security/Benefit rate

Growth rate of final output

Public investment efficiency

Raising Social Security/Benefit Spending,

\section{plus a Cut in Training Cost:}

Share of unskilled workers

Effective share of skilled workers

Effective share of public officials

Skilled unemployment rate

Unskilled unemployment rate

Headline unemployment rate

Share of corrupt officials

Social Security/Benefit rate

Growth rate of final output

Public investment efficiency

作

Absolute Deviations from Baseline

c/ An increase in $v_{s}$ by 10 percent, financed by a 10 percent cut in $v_{0}$.

$d / A n$ increase in $v_{s}$ and $\mu$ each by 10 percent, financed by a 20 percent cut in $v_{0}$.

Source: Authors' calculations.

\begin{tabular}{|c|c|c|c|c|c|c|c|c|}
\hline \multirow{3}{*}{ Baseline } & \multicolumn{8}{|c|}{ (1) } \\
\hline & \multicolumn{2}{|c|}{ Benchmark } & \multicolumn{2}{|c|}{ Endogenous $\psi$} & \multicolumn{2}{|c|}{ Endogenous $\mathrm{p}$} & \multicolumn{2}{|c|}{$\delta=1.0$} \\
\hline & Impact & Steady-state & Impact & Steady-state & Impact & Steady-state & Impact & Steady-state \\
\hline 0.847 & 0.000 & -0.002 & 0.000 & -0.002 & 0.000 & -0.002 & 0.000 & -0.002 \\
\hline 0.141 & 0.000 & 0.002 & 0.000 & 0.002 & 0.000 & 0.002 & 0.000 & 0.002 \\
\hline 0.002 & 0.000 & 0.000 & 0.000 & 0.000 & 0.000 & 0.000 & 0.000 & 0.000 \\
\hline 0.036 & 0.001 & 0.003 & 0.001 & 0.003 & 0.001 & 0.003 & 0.001 & 0.003 \\
\hline 0.106 & 0.002 & 0.008 & 0.002 & 0.008 & 0.002 & 0.008 & 0.002 & 0.008 \\
\hline 0.104 & 0.002 & 0.008 & 0.002 & 0.008 & 0.002 & 0.008 & 0.002 & 0.008 \\
\hline 0.336 & -0.003 & -0.006 & -0.003 & -0.003 & -0.002 & 0.001 & -0.002 & -0.004 \\
\hline 0.020 & 0.002 & 0.000 & 0.002 & 0.000 & 0.002 & 0.000 & 0.002 & 0.000 \\
\hline 0.047 & -0.002 & -0.001 & -0.002 & -0.001 & -0.002 & -0.001 & -0.002 & -0.001 \\
\hline 0.285 & 0.000 & 0.000 & 0.000 & 0.001 & 0.000 & -0.001 & 0.000 & 0.000 \\
\hline \multirow{3}{*}{ Baseline } & \multicolumn{8}{|c|}{ Absolute Deviations from Baseline } \\
\hline & \multicolumn{2}{|c|}{ Benchmark } & \multicolumn{2}{|c|}{ Endogenous $\psi$} & \multicolumn{2}{|c|}{ Endogenous $p$} & \multicolumn{2}{|c|}{$\delta=1.0$} \\
\hline & Impact & Steady-state & Impact & Steady-state & Impact & Steady-state & Impact & Steady-state \\
\hline 0.847 & -0.003 & -0.008 & -0.003 & -0.008 & -0.003 & -0.007 & -0.003 & -0.008 \\
\hline 0.141 & 0.003 & 0.007 & 0.003 & 0.006 & 0.003 & 0.006 & 0.003 & 0.007 \\
\hline 0.002 & 0.000 & 0.000 & 0.000 & 0.000 & 0.000 & 0.000 & 0.000 & 0.000 \\
\hline 0.036 & 0.003 & 0.007 & 0.003 & 0.006 & 0.003 & 0.006 & 0.003 & 0.006 \\
\hline 0.106 & 0.000 & 0.004 & 0.000 & 0.005 & 0.000 & 0.005 & 0.000 & 0.005 \\
\hline 0.104 & 0.000 & 0.005 & 0.000 & 0.005 & 0.000 & 0.005 & 0.000 & 0.005 \\
\hline 0.336 & -0.057 & -0.090 & -0.055 & -0.047 & -0.038 & -0.022 & -0.031 & -0.042 \\
\hline 0.020 & 0.002 & 0.000 & 0.002 & 0.000 & 0.002 & 0.000 & 0.002 & 0.000 \\
\hline 0.047 & -0.003 & 0.001 & -0.003 & 0.000 & -0.003 & 0.000 & -0.003 & 0.001 \\
\hline 0.285 & 0.002 & 0.004 & 0.002 & 0.015 & -0.001 & -0.003 & -0.001 & 0.000 \\
\hline
\end{tabular}


Table 6

Policy Experiment Results for (i) a Reduction in Unskilled Workers' Union Mark-up, and (ii) Ambitious Social Reform Programme

Reduction in Unskiled Workers' Union Mark-up: ${ }^{\mathrm{e}}$

Share of unskilled workers

Effective share of skilled workers

Effective share of public officials

Skilled unemployment rate

Unskilled unemployment rate

Headline unemployment rate

Share of corrupt officials

Social Security/Benefit rate

Growth rate of final output

Public investment efficiency

\section{Ambitious Social Reform:}

\section{Social Intervention \& Job Creation: ${ }^{\mathrm{f}}$}

Share of unskilled workers

Effective share of skilled workers

Effective share of public officials

Skilled unemployment rate

Unskilled unemployment rate

Headline unemployment rate

Share of corrupt officials

Social Security/Benefit rate

Growth rate of final output

Public investment efficiency

\begin{tabular}{|c|c|c|c|c|c|c|c|c|}
\hline \multirow{3}{*}{ Baseline } & \multicolumn{8}{|c|}{ Absolute Deviations from Baseline } \\
\hline & \multicolumn{2}{|c|}{ Benchmark } & \multicolumn{2}{|c|}{ Endogenous $\psi$} & \multicolumn{2}{|c|}{ Endogenous $p$} & \multicolumn{2}{|c|}{$\delta=1.0$} \\
\hline & Impact & Steady-state & Impact & Steady-state & Impact & Steady-state & Impact & Steady-state \\
\hline 0.847 & 0.000 & 0.000 & 0.000 & 0.000 & 0.000 & 0.001 & 0.000 & 0.000 \\
\hline 0.141 & 0.000 & 0.000 & 0.000 & 0.000 & 0.000 & 0.000 & 0.000 & 0.000 \\
\hline 0.002 & 0.000 & 0.000 & 0.000 & 0.000 & 0.000 & 0.000 & 0.000 & 0.000 \\
\hline 0.036 & 0.000 & 0.001 & 0.000 & 0.001 & 0.000 & 0.001 & 0.000 & 0.001 \\
\hline 0.106 & -0.001 & -0.003 & -0.001 & -0.003 & -0.001 & -0.003 & -0.001 & -0.003 \\
\hline 0.104 & -0.001 & -0.003 & -0.001 & -0.003 & -0.001 & -0.003 & -0.001 & -0.003 \\
\hline 0.336 & -0.002 & -0.028 & -0.003 & -0.017 & -0.002 & -0.005 & -0.001 & -0.013 \\
\hline 0.020 & 0.000 & 0.000 & 0.000 & 0.000 & 0.000 & 0.000 & 0.000 & 0.000 \\
\hline 0.047 & 0.000 & -0.001 & 0.000 & -0.001 & 0.000 & -0.001 & 0.000 & -0.001 \\
\hline 0.285 & 0.000 & 0.003 & 0.000 & 0.006 & 0.000 & 0.000 & 0.000 & 0.001 \\
\hline \multirow{3}{*}{ Baseline } & \multicolumn{8}{|c|}{ Absolute Deviations from Baseline } \\
\hline & \multicolumn{2}{|c|}{ Benchmark } & \multicolumn{2}{|c|}{ Endogenous $\psi$} & \multicolumn{2}{|c|}{ Endogenous $p$} & \multicolumn{2}{|c|}{$\delta=1.0$} \\
\hline & Impact & Steady-state & Impact & Steady-state & Impact & Steady-state & Impact & Steady-state \\
\hline 0.847 & -0.006 & -0.015 & -0.006 & -0.013 & -0.006 & -0.012 & -0.006 & -0.014 \\
\hline 0.141 & 0.005 & 0.013 & 0.005 & 0.011 & 0.005 & 0.010 & 0.005 & 0.012 \\
\hline 0.002 & 0.000 & 0.000 & 0.000 & 0.000 & 0.000 & 0.000 & 0.000 & 0.000 \\
\hline 0.036 & 0.006 & 0.012 & 0.006 & 0.012 & 0.006 & 0.012 & 0.006 & 0.012 \\
\hline 0.106 & -0.004 & -0.006 & -0.004 & -0.005 & -0.004 & -0.004 & -0.004 & -0.005 \\
\hline 0.104 & -0.003 & -0.004 & -0.003 & -0.003 & -0.003 & -0.002 & -0.003 & -0.003 \\
\hline 0.336 & -0.127 & -0.259 & -0.124 & -0.137 & -0.081 & -0.055 & -0.068 & -0.128 \\
\hline 0.020 & 0.002 & 0.001 & 0.002 & 0.001 & 0.002 & 0.001 & 0.002 & 0.001 \\
\hline 0.047 & -0.003 & 0.003 & -0.003 & 0.000 & -0.003 & -0.001 & -0.003 & 0.001 \\
\hline 0.285 & -0.021 & -0.009 & -0.020 & 0.020 & -0.026 & -0.029 & -0.027 & -0.022 \\
\hline
\end{tabular}

e/ A reduce of $\xi^{U}$ by 10 percent, which translates to wage mark-up going from 1.23 times to 1.20 times.

$\mathrm{f} / \mathrm{An}$ increase in $v_{\mathrm{S}}$ by 10 percent, a training cost cut, $\mu$, by 20 percent, and a reduction in $\xi^{\cup}$ by 20 percent, which translates to 1.17 times of mark-up.

Source: Authors' calculations. 
Table 7

Policy Experiment Results for (i) An Increase in the Share of Public Investment, and (ii) Ambitious Social Reform, plus an Increase in Share of Public Investment,

with Models with Endogenous Threshold for Corruption

\begin{tabular}{|c|c|c|c|c|c|c|c|c|c|c|c|}
\hline \multirow[b]{3}{*}{ An Increase in the Share of Public Investment: ${ }^{g}$} & \multirow{3}{*}{ Baseline } & \multicolumn{8}{|c|}{ Absolute Deviations from Baseline } & & \\
\hline & & \multicolumn{2}{|c|}{ Benchmark } & \multicolumn{2}{|c|}{ Endogenous $\psi$} & \multicolumn{2}{|c|}{ Endogenous $p$} & \multicolumn{2}{|c|}{$\delta=1.0$} & & \\
\hline & & Impact & Steady-state & Impact & Steady-state & Impact & Steady-state & Impact & Steady-state & & \\
\hline Share of unskilled workers & 0.847 & 0.000 & 0.000 & 0.000 & 0.000 & 0.000 & 0.000 & 0.000 & 0.000 & & \\
\hline Effective share of skilled workers & 0.141 & 0.000 & 0.000 & 0.000 & 0.000 & 0.000 & 0.000 & 0.000 & 0.000 & & \\
\hline Effective share of public officials & 0.002 & 0.000 & 0.000 & 0.000 & 0.000 & 0.000 & 0.000 & 0.000 & 0.000 & & \\
\hline Skilled unemployment rate & 0.036 & 0.000 & 0.000 & 0.000 & 0.000 & 0.000 & 0.000 & 0.000 & 0.000 & & \\
\hline Unskilled unemployment rate & 0.106 & 0.000 & 0.000 & 0.000 & 0.000 & 0.000 & 0.000 & 0.000 & 0.000 & & \\
\hline Headline unemployment rate & 0.104 & 0.000 & 0.000 & 0.000 & 0.000 & 0.000 & 0.000 & 0.000 & 0.000 & & \\
\hline Share of corrupt officials & 0.336 & 0.000 & 0.000 & 0.000 & 0.000 & 0.000 & 0.000 & 0.000 & 0.000 & & \\
\hline Social Security/Benefit rate & 0.020 & 0.000 & 0.000 & 0.000 & 0.000 & 0.000 & 0.000 & 0.000 & 0.000 & & \\
\hline Growth rate of final output & 0.047 & 0.000 & 0.000 & 0.000 & 0.000 & 0.000 & 0.000 & 0.000 & 0.000 & & \\
\hline Public investment efficiency & 0.285 & -0.026 & -0.026 & -0.026 & -0.026 & -0.026 & -0.026 & -0.042 & -0.043 & & \\
\hline \multirow{3}{*}{$\begin{array}{l}\text { Ambitious Social Reform, coupled with An Increase } \\
\text { in the Share of Public Investment: }\end{array}$} & \multirow{3}{*}{ Baseline } & \multicolumn{10}{|c|}{ Absolute Deviations from Baseline } \\
\hline & & \multicolumn{2}{|c|}{$\begin{array}{c}\text { Benchmark (without } \\
\text { switching) }\end{array}$} & \multicolumn{2}{|c|}{$\begin{array}{c}\text { Benchmark } \\
\text { switching) }\end{array}$} & \multicolumn{2}{|c|}{ Endogenous $\psi$} & \multicolumn{2}{|c|}{ Endogenous $p$} & \multicolumn{2}{|c|}{$\delta=1.0$} \\
\hline & & Impact & Steady-state & Impact & Steady-state & Impact & Steady-state & Impact & $\begin{array}{l}\text { Steady-state } \\
\end{array}$ & Impact & Steady-state \\
\hline Share of unskilled workers & 0.847 & -0.006 & -0.015 & -0.006 & -0.001 & -0.006 & -0.013 & -0.006 & -0.012 & -0.006 & -0.014 \\
\hline Effective share of skilled workers & 0.141 & 0.005 & 0.013 & 0.005 & 0.001 & 0.005 & 0.011 & 0.005 & 0.010 & 0.005 & 0.012 \\
\hline Effective share of public officials & 0.002 & 0.000 & 0.000 & 0.000 & 0.000 & 0.000 & 0.000 & 0.000 & 0.000 & 0.000 & 0.000 \\
\hline Skilled unemployment rate & 0.036 & 0.006 & 0.012 & 0.006 & 0.002 & 0.006 & 0.012 & 0.006 & 0.012 & 0.006 & 0.012 \\
\hline Unskilled unemployment rate & 0.106 & -0.004 & -0.006 & -0.004 & 0.001 & -0.004 & -0.005 & -0.004 & -0.004 & -0.004 & -0.005 \\
\hline Headline unemployment rate & 0.104 & -0.003 & -0.004 & -0.003 & 0.000 & -0.003 & -0.003 & -0.003 & -0.002 & -0.003 & -0.003 \\
\hline Share of corrupt officials & 0.336 & -0.127 & -0.260 & -0.127 & -0.336 & -0.124 & -0.138 & -0.081 & -0.056 & -0.068 & -0.128 \\
\hline Social Security/Benefit rate & 0.020 & 0.002 & 0.002 & 0.002 & 0.001 & 0.002 & 0.002 & 0.002 & 0.001 & 0.002 & 0.002 \\
\hline Growth rate of final output & 0.047 & -0.003 & 0.003 & -0.003 & 0.004 & -0.003 & 0.000 & -0.003 & 0.000 & -0.003 & 0.001 \\
\hline Public investment efficiency & 0.285 & -0.021 & -0.008 & -0.021 & 0.716 & -0.020 & 0.020 & -0.026 & -0.029 & -0.027 & -0.020 \\
\hline
\end{tabular}

$\mathrm{g} /$ An increase in $v_{1}$ by 10 percent, financed by a 10 percent cut in $v_{0}$.

$\mathrm{h} / \mathrm{An}$ increase in $v_{s}$ band $v_{1}$ by 10 percents, a training cost cut, $\mu$, by 20 percent, and a reduction in $\xi^{U}$ by 20 percent, which translates to 1.17 times of mark-up.

Source: Authors' calculations. 
Figure 1

Public Sector Downsizing

(Absolute deviations from baseline)

\section{- Benchmark}

— Endogenous monitoring intensity

$$
\begin{aligned}
& - \text { Endogenous } \psi \\
& \cdots \cdots \cdots \\
& \cdots \cdots
\end{aligned}
$$

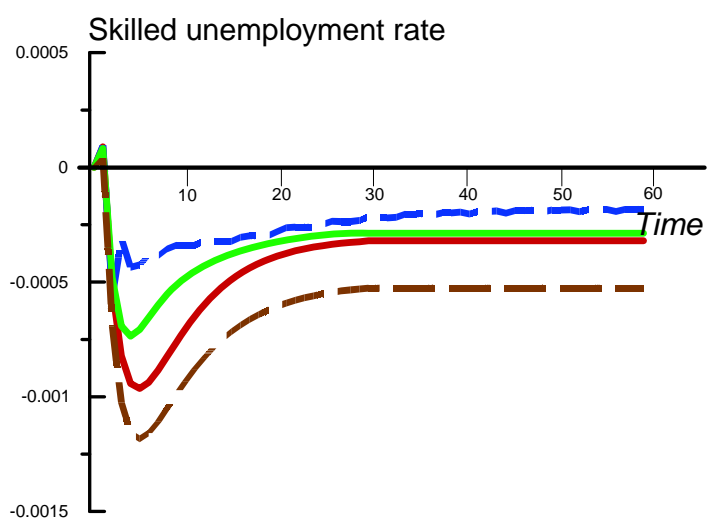

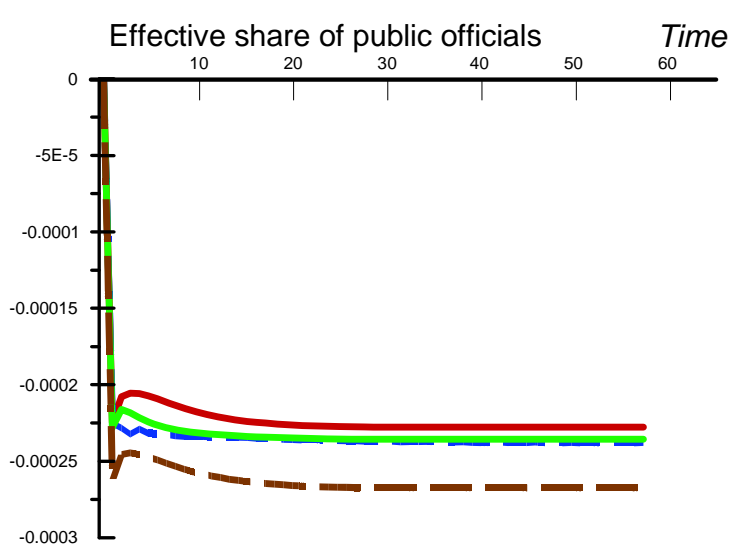

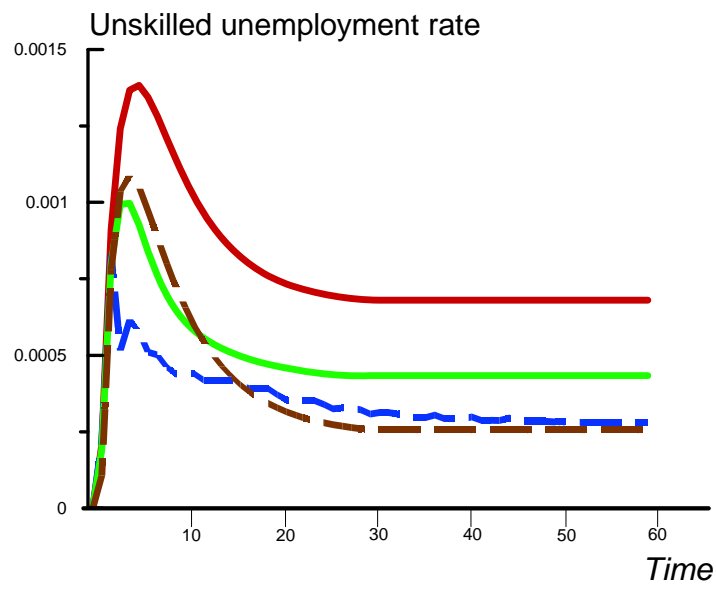

Share of corrupt officials

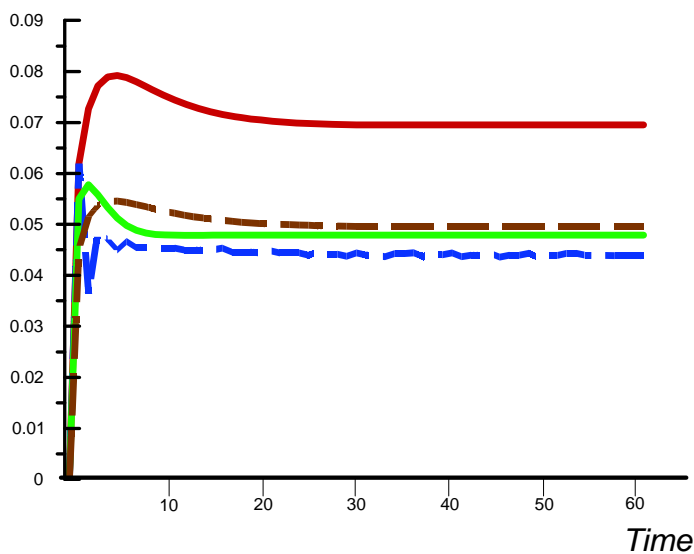

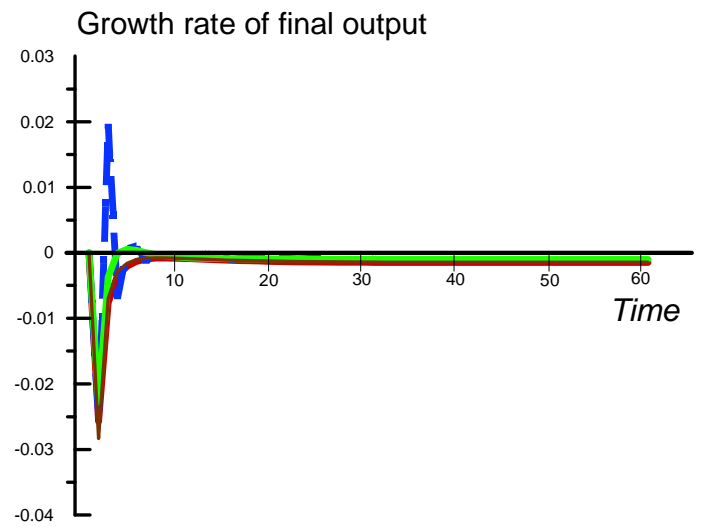

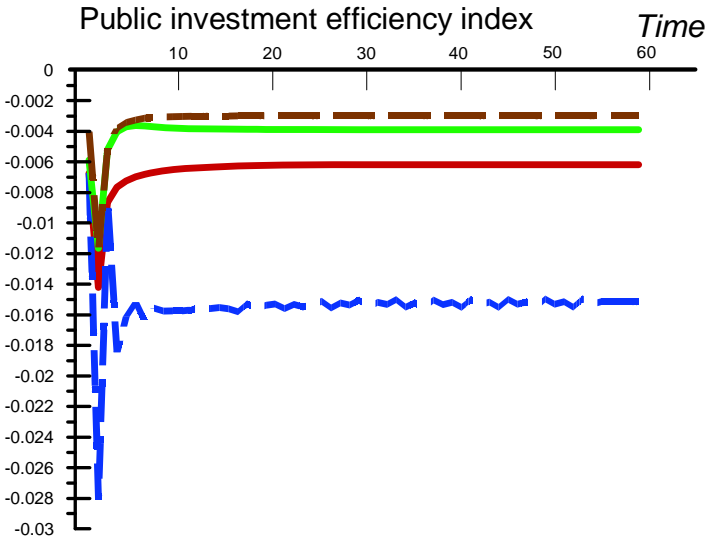


Figure 2

An Increase in the Share of Social Security / Benefit Spending

(Absolute deviations from baseline)

\section{- Benchmark}

_- Endogenous monitoring intensity

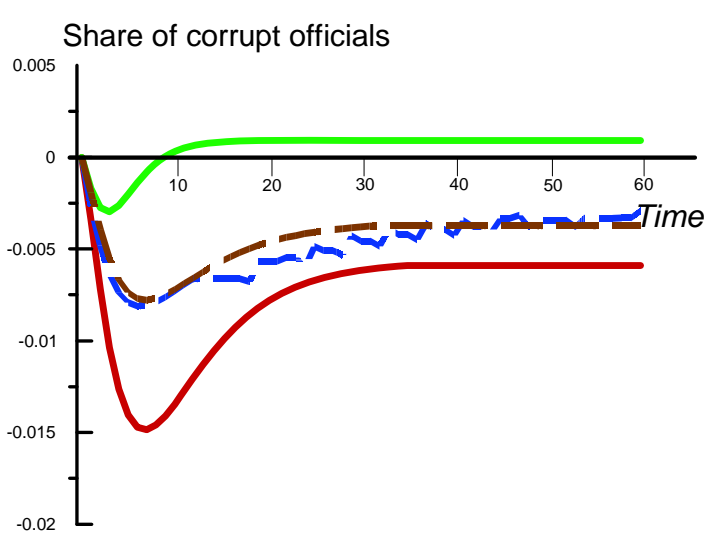

\section{- - Endogenous $\psi$}

$$
\delta=1.0
$$
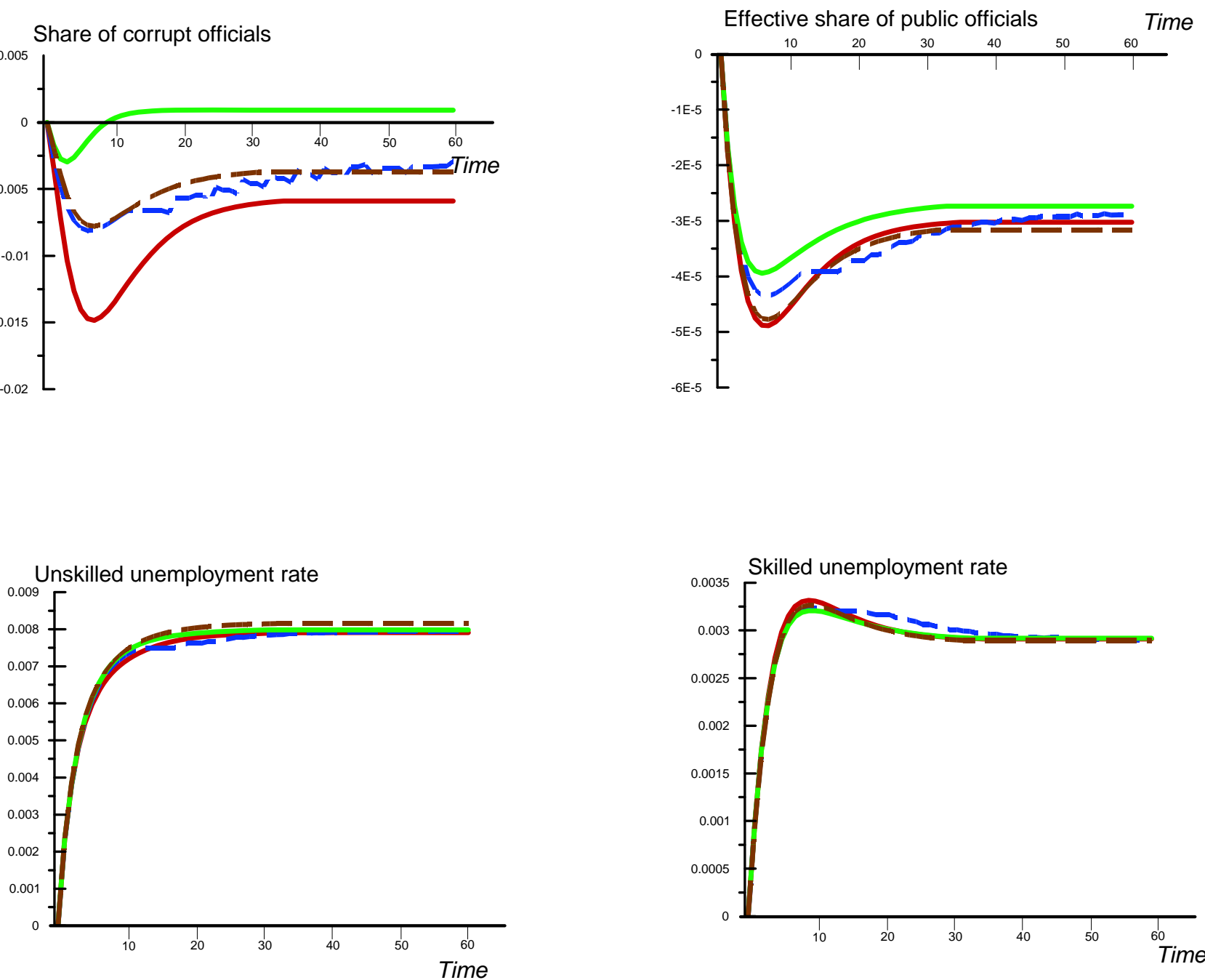

Growth rate of final output

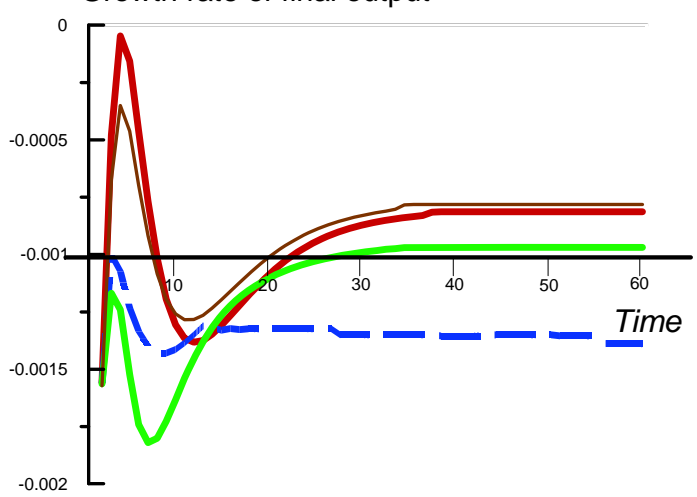

Public investment efficiency index

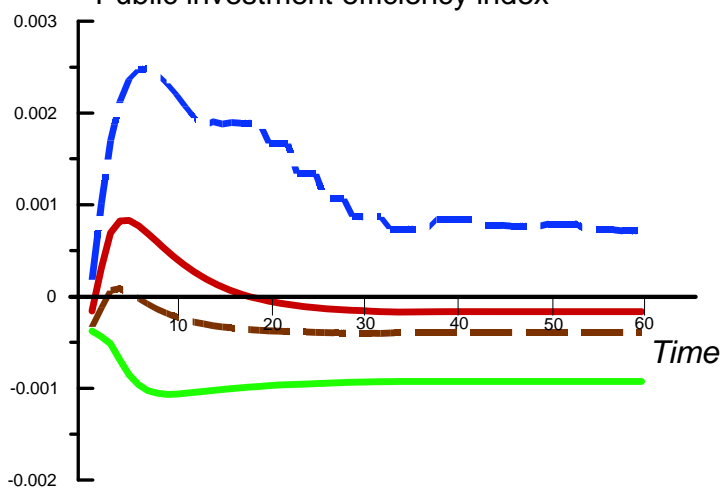


Figure 3

Reduction in Unskiled Workers' Union Wage Mark-up

(Absolute deviations from baseline)

\section{- Benchmark}

_- Endogenous monitoring intensity
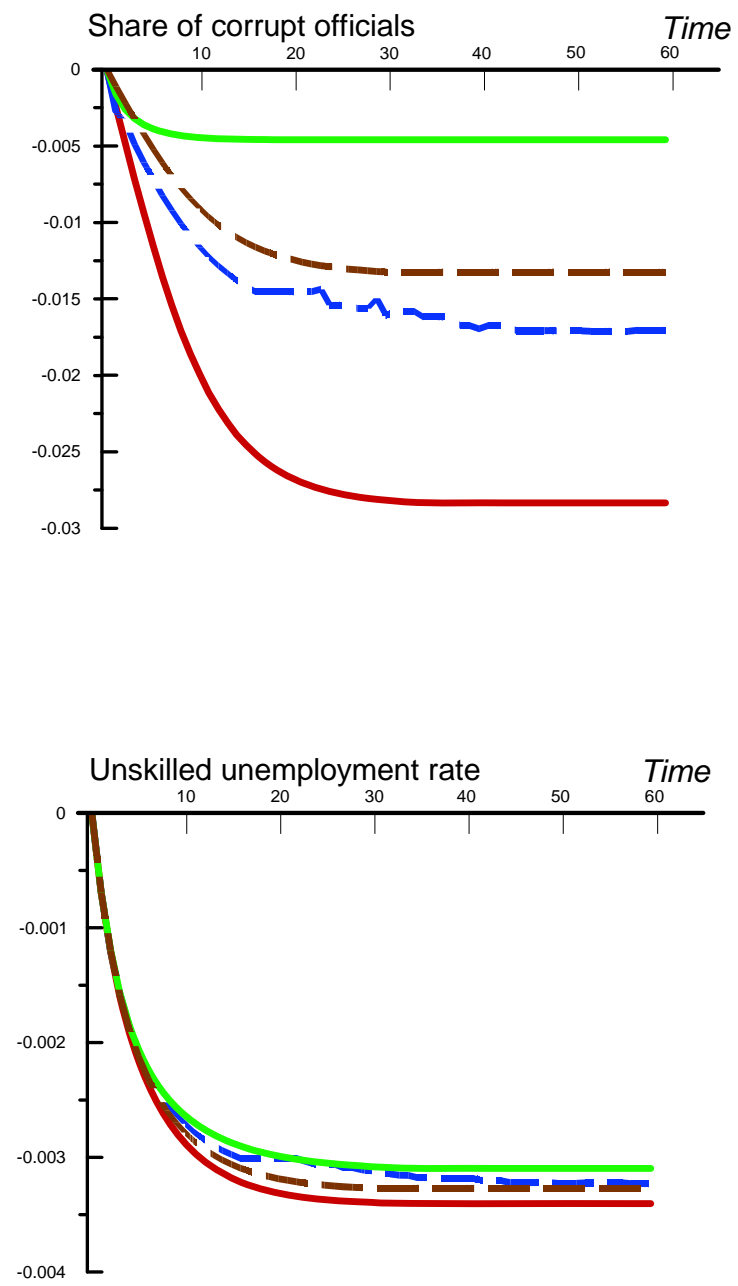

Growth rate of final output

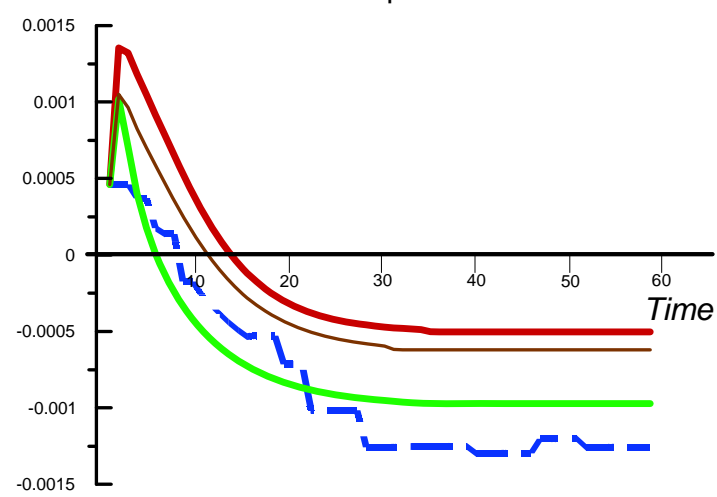

\section{- - Endogenous $\psi$}

$\delta=1.0$

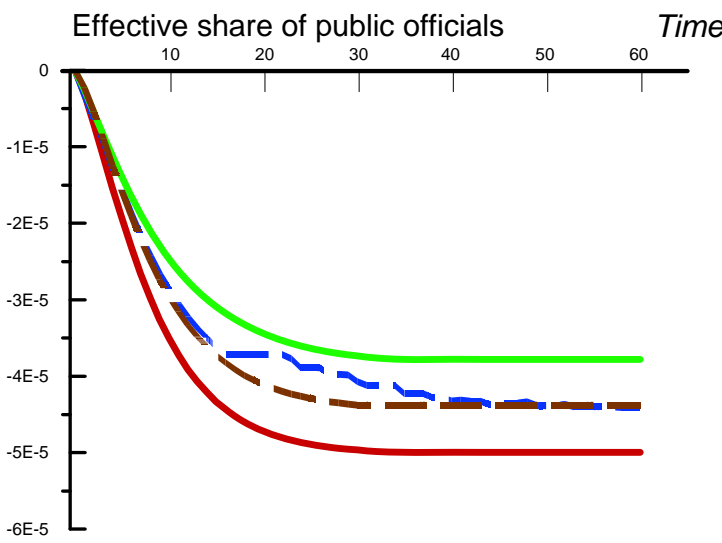

Public investment efficiency index

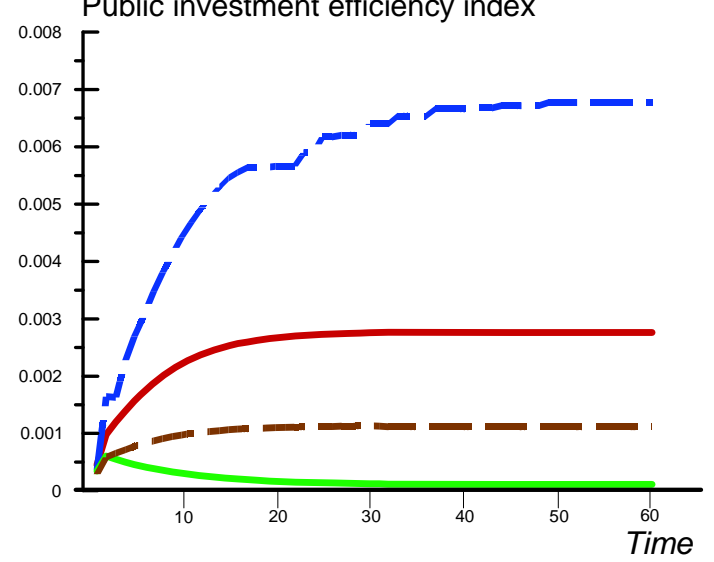


Figure 4

Ambitious Social Reform, coupled with an Increase in Share of Public Investment (Absolute deviations from baseline)
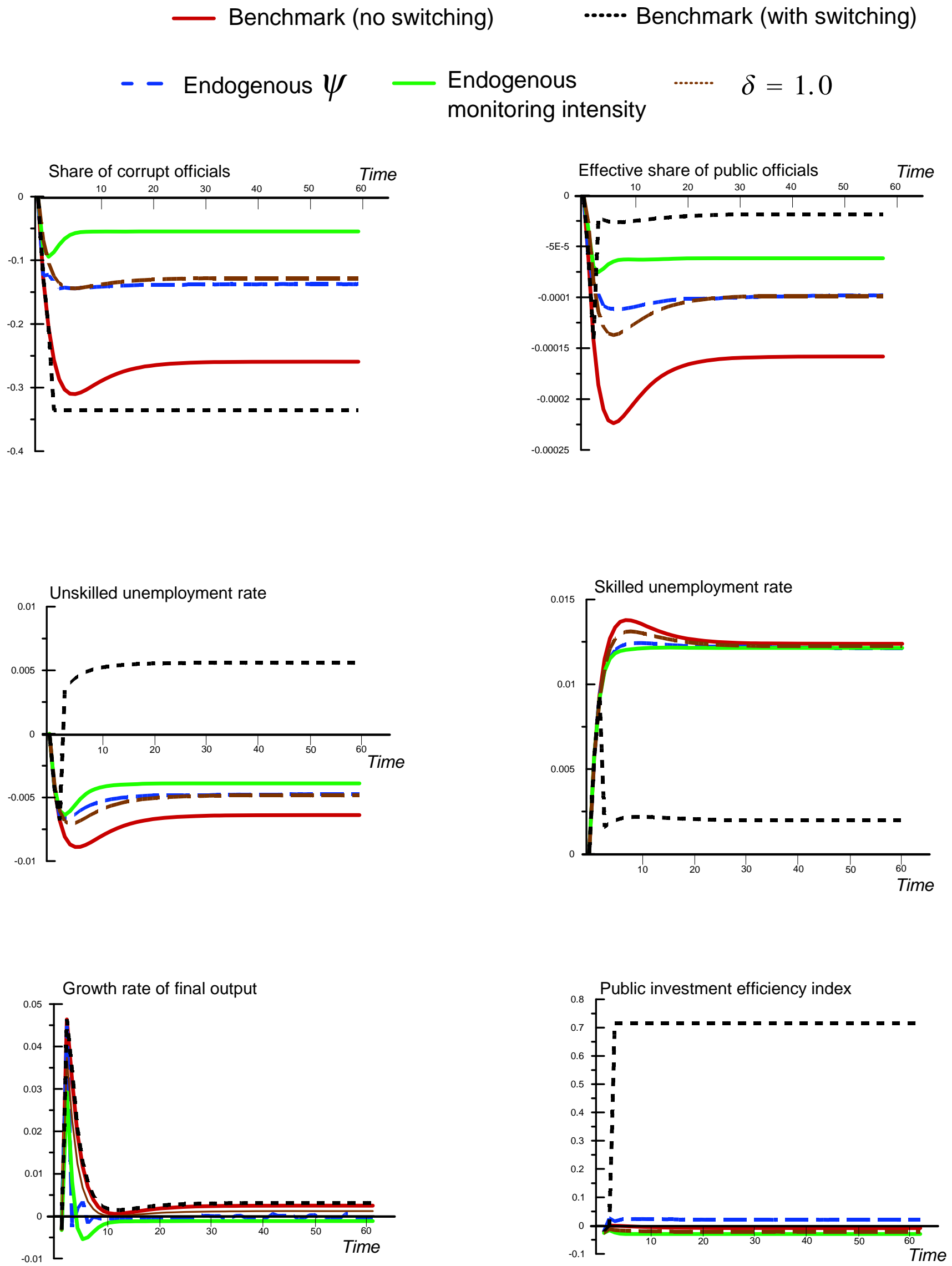